\title{
MARCO JURÍDICO DE LA EXTRACCIÓN DE HIDROCARBUROS MEDIANTE FRACTURA HIDRÁULICA EN LA COMUNIDAD AUTÓNOMA DEL PAÍS VASCO
}

\author{
ENARA ZARRABEITIA BILBAO \\ Ingeniera en organización industrial y doctora por la UPV/EHU \\ enara.zarrabeitia@ehu.eus \\ DANIEl MAeZTU PÉREZ \\ Licenciado en Derecho y máster en Derecho Ambiental \\ danimaeztu@gmail.com \\ IZASKUN ÁlVAREZ MEAZA \\ Ingeniera industrial y doctora por la UPV/EHU \\ izaskun.alvarez@ehu.eus \\ ITZIAR MARTÍNEZ DE ALEGRÍA MANCISIDOR \\ Licenciada en Ciencias Económicas y Empresariales y doctora por la UPV/EHU \\ itziar.martinezdealegria@ehu.eus
}

Recibido: 23 de marzo de 2016 / Aceptado: 19 de mayo de 2016

RESUMEN: El agotamiento de las fuentes de energía fósil de fácil acceso y de gran rendimiento y la dependencia energética de los países europeos en general (y de España en particular) han propiciado un nuevo contexto de crisis energética y económica. En esta tesitura, el interés que ha suscitado la extracción de hidrocarburos no convencionales mediante la técnica de fractura hidráulica o fracking es un hecho indiscutible. Sin embargo, el afianzamiento de esta técnica en el panorama extractor de recursos energéticos lleva aparejada una considerable oposición social. En la mayoría de 
lugares, los beneficios proclamados por sus defensores no han conseguido aplacar la contestación ciudadana al fracking. Es en esta nueva coyuntura, precisamente, donde se sitúa el debate sobre la regulación jurídica del fracking. Con todo, el siguiente trabajo tiene como objetivo profundizar en el posicionamiento de la Comunidad Autónoma del País Vasco en relación con esta técnica, y, concretamente, analizar la génesis, el proceso de elaboración y la aprobación de la Ley 6/2015, de 30 de junio, de medidas adicionales de protección medioambiental para la extracción de hidrocarburos no convencionales y la fractura hidráulica o fracking, promovida a través de una iniciativa legislativa popular.

RESUM: L'esgotament de les fonts d'energia fòssil de fàcil accés i de gran rendiment, i la dependència energètica dels països europeus en general (i d'Espanya en particular), han propiciat un nou context de crisi energètica i econòmica. En aquesta tessitura, l'interès que ha suscitat l'extracció d'hidrocarburs no convencionals mitjançant la tècnica de fractura hidràulica o fracking es tracta d'un fet indiscutible. No obstant això, la consolidació d'aquesta tècnica en el panorama extractor de recursos energètics ha arribat aparellat amb una considerable oposició social. En la majoria de llocs, els beneficis proclamats pels seus defensors no han aconseguit aplacar la contestació ciutadana al fracking. És en aquesta nova conjuntura, precisament, on se situa el debat sobre la regulació jurídica del fracking. Amb tot, en el següent treball es té com a objectiu aprofundir en el posicionament de la Comunitat Autònoma del País Basc en relació amb aquesta tècnica, i concretament, analitzar la gènesi, el procés d'elaboració i l'aprovació de la Llei 6/2015, de 30 de juny, de mesures addicionals de protecció mediambiental per a l'extracció d'hidrocarburs no convencionals i la fractura hidràulica o fracking, promoguda a través d'una iniciativa legislativa popular.

ABSTRACT: The depletion of easily accessible, high performance fossil energy sources and the energy dependence of the European countries in general (and of Spain in particular) have led to a new context of energy and economic crisis. In this situation, the extraction of unconventional hydrocarbons using the technique of hydraulic fracturing or fracking has aroused considerable interest. However, the fact that it has found a place among the techniques used for extracting energy resources has created considerable social opposition. In most places, the benefits proclaimed by its advocates 
have failed to placate the public response to fracking. This new situation has sparked a debate on the legal regulation of fracking. The aim of this study is to analyse where the Basque Country stands with respect to this technique, and specifically to analyze the genesis, the process of development and the approval of the Act $6 / 2015$, of June 30 , on additional environmental protection measures for the extraction of unconventional hydrocarbons and hydraulic fracturing or fracking, the result of a legislative initiative of the Basque people themselves.

PALABRAS CLAVE: fractura hidráulica - hidrocarburos no convencionales Comunidad Autónoma del País Vasco - iniciativa legislativa popular.

PARAULES CLAU: Fractura hidràulica - hidrocarburs no convencionals Comunitat Autònoma del País Basc — Iniciativa Legislativa Popular.

KEYWORDS: Fracking - unconventional hydrocarbons - Basque Country Popular Legislative Initiative.

\begin{abstract}
Sumario: I. Introducción. El debate sobre la regulación jurídica de la fractura hidráulica. II. Marco jurídico de la extracción de hidrocarburos mediante fractura hidráulica a nivel internacional y en la Unión Europea. 1. La fractura hidráulica a nivel internacional. El caso de los Estados Unidos. 2. La fractura hidráulica a nivel europeo. III. Marco jurídico de la extracción de hidrocarburos mediante fractura hidráulica a nivel español. 1. Sumario de las competencias del Estado en la materia. 2. Marco regulatorio de la exploración, investigación y explotación de gas no convencional en España. 3. La doctrina del Tribunal Constitucional. IV. Marco jurídico de la extracción de hidrocarburos mediante fractura hidráulica: reflexiones sobre el caso de la Comunidad Autónoma del País Vasco. 1. Iniciativa legislativa popular para prohibir la fractura hidráulica en la Comunidad Autónoma del País Vasco. 2. "Triple filtro legal" contra el fracking. 2.1. Primer filtro: la vía catalana. 2.2. Segundo filtro: evaluación estratégica. 2.3. Tercer filtro: Ley de Aguas. 3. Impugnación de la Ley 6/2015, de 30 de junio, ante el Tribunal Constitucional. V. Conclusiones. VI. Bibliografía.
\end{abstract}

\title{
I. INTRODUCCIÓN. EL DEBATE SOBRE LA REGULACIÓN JURÍDICA DE
}

\section{LA FRACTURA HIDRÁULICA}

En la actualidad, el interés que ha suscitado la extracción de hidrocarburos no convencionales mediante técnicas como la fractura hidráulica o fracking es un hecho indiscutible. Este debate se desarrolla tanto en el plano institucional como en el plano social. La controversia originada en este ámbito se debe, por una parte, a la revolución 
energética que ha conllevado este avance tecnológico, según sus defensores, y, por otra, a los riesgos para el medio ambiente y la salud, así como a su insostenibilidad económica, según señalan las voces críticas con esta técnica.

El agotamiento de las fuentes de energía fósil de fácil acceso y de gran rendimiento y la dependencia energética de los países europeos en general (y de España en particular) respecto a otros países han propiciado un nuevo contexto de crisis energética y económica. En ese sentido, la existencia en España de grandes cantidades de gas en yacimientos no convencionales repartidos a lo largo del subsuelo ha sido proclamada como parte de la solución a los problemas de abastecimiento y dependencia energética planteados.

La técnica del fracking consiste en inyectar a alta presión un fluido de fracturación para romper la roca y abrir y agrandar las fracturas con objeto de que los hidrocarburos fluyan al interior del pozo ${ }^{1}$. De este modo, gracias a esta técnica se consigue aprovechar los hidrocarburos no convencionales, es decir, petróleo no convencional o gas no convencional que no pueden obtenerse por mera extracción (con o sin ayuda de bombeo) de una reserva subterránea ${ }^{2}$. Sin embargo, estos recursos energéticos son más costosos de producir, su explotación implica un balance energético considerablemente menor que el de los recursos convencionales y, sobre todo, presentan un mayor impacto tanto para el medio ambiente como para la salud ${ }^{3}$.

Indudablemente, el afianzamiento de esta técnica en el panorama extractor de recursos energéticos lleva aparejada una considerable oposición social. En la mayoría de lugares, los beneficios proclamados por sus defensores no han conseguido aplacar la contestación ciudadana a la fractura hidráulica. Es en esta nueva coyuntura, precisamente, donde se sitúa el debate sobre la regulación jurídica de la fractura hidráulica o fracking.

En el caso de España, el posicionamiento adoptado por el Gobierno central es favorable a la fractura hidráulica. De hecho, así lo ha demostrado tanto en el plano de su discurso

\footnotetext{
${ }^{1}$ COMISIÓN EUROPEA, Comunicación sobre la exploración y producción de hidrocarburos (como el gas de esquisto) utilizando la fracturación hidráulica de alto volumen en la UE, COM(2014) 23 final, 22 de enero de 2014, p. 6. Recuperado el 17 de septiembre de 2015, de http://eur-lex.europa.eu/legalcontent/ES/TXT/PDF/?uri=CELEX:52014DC0023\&from=ES.

${ }^{2}$ LA ENCICLOPEDIA DE CIENCIAS Y TECNOLOGÍAS EN ARGENTINA. Recuperado el 18 de septiembre de 2015, de http://cyt-ar.com.ar/cyt-ar/index.php/Hidrocarburo_no_convencional.

${ }^{3}$ MARZO, M., "Recursos convencionales y no convencionales de petróleo y gas", Enseñanza de las Ciencias de la Tierra, 2008, p. 222.
} 
energético como a nivel legislativo y de práctica política. Sin embargo, impulsadas por la gran contestación social contra el fracking en aquellos lugares que son objetivo de la fractura hidráulica, instituciones diversas (y de diferente signo político) como ayuntamientos, diputaciones o gobiernos de comunidades autónomas se han opuesto a la práctica de esta técnica en su territorio. Concretamente, las comunidades autónomas de Cantabria, La Rioja, Navarra, Cataluña, Andalucía y País Vasco han convertido esta oposición social en oposición política e institucional, elaborando y aprobando, con mayor o menor éxito, leyes precisas sobre esta cuestión con el objetivo de prohibir esta técnica en su comunidad.

En esta tesitura, en las siguientes líneas se tiene como objetivo profundizar en el posicionamiento de la Comunidad Autónoma del País Vasco en relación con el fracking, y, concretamente, analizar la génesis, el proceso de elaboración y la aprobación de la Ley 6/2015, de 30 de junio, de medidas adicionales de protección medioambiental para la extracción de hidrocarburos no convencionales y la fractura hidráulica o fracking. No obstante, con objeto de contextualizar el caso vasco, se parte del análisis del estado de la cuestión a nivel internacional, europeo y español.

\section{MARCO JURÍDICO DE LA EXTRACCIÓN DE HIDROCARBUROS MEDIANTE FRACTURA HIDRÁULICA A NIVEL INTERNACIONAL Y EN LA UNIÓN EUROPEA}

A continuación se expondrá una síntesis de la situación de la fractura hidráulica a nivel internacional y europeo, ahondando especialmente en el profuso y controvertido marco normativo.

\section{La fractura hidráulica a nivel internacional. El caso de los Estados Unidos}

En la actualidad se emplea la técnica del fracking en varios territorios y con distinta intensidad. Sin embargo, hasta la fecha el número de países que cuentan con explotaciones comerciales es escaso: Estados Unidos, Canadá, México y China, 
principalmente. No obstante, otros muchos territorios han puesto en marcha plantas de experimentación o están considerando su uso ${ }^{4}$.

Los Estados Unidos, además de ser pioneros en el desarrollo de la tecnología relacionada con la fractura hidráulica, también lo son en el uso de esta práctica para explotar sus hidrocarburos no convencionales. A día de hoy, el fracking no ha sido aún utilizado como método de explotación en ningún yacimiento fuera de los Estados Unidos tan masivamente como en este país, a pesar de que las explotaciones ya han comenzado en diferentes lugares ${ }^{5}$.

Precisamente, en los Estados Unidos la industria del gas y del petróleo ya está empleando el fracking (o pretende hacerlo) en 31 estados, donde ya hay más de 500.000 pozos activos de gas natural. El gas no convencional representa en la actualidad una cuarta parte de toda la producción de gas de los Estados Unidos, y la Administración de Información de Energía (Energy Information Administration, EIA) prevé que esta proporción se duplicará para el año 2035. Los estados donde más se practica el fracking son Pensilvania, Ohio, Virginia Occidental, Oklahoma y Texas ${ }^{6,7}$.

En este sentido, el primer hito de consideración en la consolidación de esta técnica se produce en 1998, año en el que comienza a funcionar la primera explotación comercialmente viable en el yacimiento Barnett, Texas. Su explotación corrió a cargo de la empresa Mitchell's Energy (hoy absorbida por Devon). El segundo hito, de carácter jurídico, es el impulso dado al sector por parte de la administración encabezada por George W. Bush con la aprobación de la Energy Policy Act $(2005)^{8}$, que exime al sector de cumplir o, en su caso, avala el incumplimiento de varias leyes federales y normativas ambientales, por lo que el fracking comienza a extenderse rápidamente por diferentes yacimientos y estados 9 .

\footnotetext{
${ }^{4}$ AYLLÓN, J. M., "El agua, sin gas, por favor: la controversia jurídica en torno al fracking en España", eXtoikos, 2014, p. 35.

${ }^{5}$ FRACKING EZ ARABA, “Estado de la cuestión: ¿Dónde se hace fracking?”, Fracking Ez Araba (dir.), Fracking, una apuesta peligrosa, Vitoria-Gasteiz, 2012, pp. 21-22.

${ }^{6}$ CINGOTTI, N., Fracking: un pozo sin fondo, Dossier Informativo, marzo de 2014, p. 4.

${ }^{7}$ BRADY, W., "Hydraulic Fracturing Regulation in the United States: The Laissez-Faire Approach of the Federal Government and Varying State Regulations", University of Denver, Grimshaw \& Harring, 2013, p. 19.

${ }^{8}$ ENERGY POLICY ACT, Public Law 109-58-AUG. 8, 2005. Recuperado el 20 de septiembre de 2015, de https:/www.congress.gov/bill/109th-congress/house-bill/6.
}

${ }^{9}$ AYLLÓN, "El agua..." cit., p. 35. 
Por otro lado, los estados son libres de regular la fractura hidráulica como estimen oportuno y según sus intereses, con la excepción de que las regulaciones estatales deben cumplir los requisitos mínimos de los reglamentos federales aplicables. Así pues, la mayor parte de la responsabilidad de la regulación del fracking recae en los diversos estados, cuyas regulaciones divergen ampliamente entre sí en complejidad y nivel de protección de la salud humana y del medio ambiente ${ }^{10}$. Vermont, Nueva Jersey, Nueva York, Colorado, Texas, Ohio y Pensilvania, por ejemplo, incluyen prohibiciones, moratorias y restricciones de zonas a escala local o estatal ${ }^{11}$.

Con todo, a pesar de que los Estados Unidos son el motor del fracking y los impulsores de esta técnica en el resto del mundo, la producción de gas natural está escasamente regulada tanto a escala federal como local.

\section{La fractura hidráulica a nivel europeo}

Los defensores del gas no convencional presentaron el auge y esplendor de esta técnica en los Estados Unidos como una historia de éxito sin precedentes que Europa debía emular. Sin embargo, además de unas reservas mucho menores, son varios los factores que hacen improbable un desarrollo similar en Europa: las diferencias geológicas, geográficas e hidrológicas, y la falta de infraestructuras y conocimientos adecuados ${ }^{12}$. A todo ello se suma un factor especulativo importante, cada vez más repetido, que habla de una burbuja financiera creada por unos precios del gas inducidos artificialmente y de una producción que declina muy rápidamente, lo que podría conducir al fín anticipado de este sueño energético ${ }^{13}$. Además, a todo ello se suma la oposición pública al fracking, que se está extendiendo por todo el continente europeo a medida que la ciudadanía va tomando conciencia de los riesgos potenciales de esta práctica.

Así pues, a día de hoy no existen explotaciones de hidrocarburos no convencionales a nivel comercial en la Unión Europea.

\footnotetext{
${ }^{10}$ BRADY, "Hydraulic..." cit., pp. 10-11.

${ }^{11}$ CINGOTTI, Fracking... cit., p. 4.

${ }^{12}$ FLUES, F., A slow costly road to nowhere: shale gas development in Europe. Recuperado el 25 de septiembre de 2015 , de http://www.foeeurope.org/sites/default/files/foee_slow_and_costly_road_may2013.pdf.

${ }^{13}$ MARTÍN-SOLA, S., "Fracking: estado de situación en otros países”, Ecologista, 2013. Recuperado el 26 de septiembre de 2015, de http://www.ecologistasenaccion.org/article24516.html.
} 
En lo que respecta a la posición de los Estados miembros de la Unión Europea en relación con el fracking, algunos países han respondido al uso potencial de esta práctica con moratorias, prohibiciones de hecho o regulaciones ambientales más severas. Varios Estados europeos se muestran contrarios a la fractura hidráulica hasta que se despejen las incógnitas relativas a su inocuidad y rentabilidad, en aplicación del principio ambiental de cautela, como es el caso, hasta el momento, de Francia, Bulgaria, Italia, Alemania, la República Checa y Luxemburgo ${ }^{14}$. No obstante, otros Estados, se muestran favorables a esta técnica y han concedido autorizaciones de exploración o investigación con vistas a una futura explotación, como es el caso de Polonia, Reino Unido, Rumanía, Portugal, Estonia, Dinamarca, Hungría, Suecia, Países Bajos y España ${ }^{15,16}$.

Sin embargo, resulta imposible prohibir o permitir el fracking a escala comunitaria. En este sentido, hasta el Tratado de Lisboa la Unión Europea no disponía de base jurídica específica en materia energética. En la actualidad, la energía se incluye entre las competencias compartidas con los Estados miembros (art. 4.2.i del Tratado de Funcionamiento de la Unión Europea, $\operatorname{TFUE}^{17}$ ), y la Unión Europea carece de la potestad para determinar las fuentes de abastecimiento energético de los Estados miembros (art. 194.2 del TFUE ${ }^{18}$ ).

No obstante, a pesar de la imposibilidad de prohibir o permitir la fractura hidráulica (o cualquier otra fuente de energía por parte de las instituciones comunitarias), dichas instituciones sí toman decisiones sobre políticas energéticas comunitarias. Estas políticas vienen marcadas por tres factores principales: la seguridad del abastecimiento en una situación de dependencia exterior, la liberalización del mercado interior de la energía y la decidida asunción de compromisos en la lucha contra el cambio climático ${ }^{19}$.

\footnotetext{
${ }^{14}$ CINGOTTI, Fracking... cit., p. 4.

${ }^{15}$ AYLLÓN, "El agua...” cit., p. 36.

${ }^{16}$ SÁNDEZ, J. D., La fracturación hidráulica en la Unión Europea: Estado de la cuestión, Instituto Español de Estudios Estratégicos, 2014, pp. 12-23.

17 “Las competencias compartidas entre la Unión y los Estados miembros se aplicarán a los siguientes ámbitos principales: [...] la energía [...]” (art. 4.2.i, TFUE).

18 "No afectarán al derecho de un Estado miembro a determinar las condiciones de explotación de sus recursos energéticos, sus posibilidades de elegir entre distintas fuentes de energía y la estructura general de su abastecimiento energético [...]" (art. 194.2, TFUE).

${ }^{19}$ SANTAMARÍA, R. J., "Las claves jurídicas del debate sobre el fracking”, Revista Catalana de Dret Ambiental, 2014, p. 4.
} 
Con todo, tomando como referencia los factores mencionados, la Unión Europea actúa en relación con la fractura hidráulica a través de diversas recomendaciones propuestas tanto por el Parlamento Europeo como por la Comisión Europea mediante informes o comunicaciones $^{20,21,22,23,24,25}$. No obstante, en dichos documentos no existe consenso en cuanto a las consideraciones, recomendaciones o actuaciones a adoptar en relación con la fractura hidráulica ${ }^{26,27}$.

Así, se observa que el fracking, en general, y su regulación, en particular, están siendo objeto de estudio y debate tanto por parte de los distintos Estados miembros como por las distintas instituciones europeas. Sin embargo, por una parte, el posicionamiento oficial de los Estados comunitarios ante la fractura hidráulica (desde su prohibición hasta su fomento) resulta muy dispar, y, por otra, los documentos comunitarios publicados se contradicen en sus conclusiones.

Por lo tanto, resulta imposible presentar un posicionamiento o una visión única respecto al fracking a nivel europeo. Además, cabe destacar que la Unión Europea no ha aprobado hasta la fecha ninguna normativa de carácter vinculante sobre la fractura hidráulica.

${ }^{20}$ PARLAMENTO EUROPEO, Repercusiones de la extracción de gas y petróleo de esquito en el medio ambiente y la salud, IP/A/ENVI/ST/2011-07, 2011, junio de 2011, p. 83. Recuperado el 7 de octubre de 2015, de http://www.europarl.europa.eu/RegData/etudes/etudes/join/2011/464425/IPOLENVI_ET\%282011\%29464425_ES.pdf.

${ }^{21}$ COMISIÓN EUROPEA, Final report on unconventional gas in Europe, 8 de noviembre de 2011, p. 101. Recuperado el 7 de octubre de 2015 , de https://ec.europa.eu/energy/sites/ener/files/documents/2012_unconventional_gas_in_europe.pdf.

${ }^{22}$ PARLAMENTO EUROPEO, Proyecto de informe sobre aspectos industriales, energéticos y otros del gas y del petróleo de esquisto, 2011/2309(INI), 25 de septiembre de 2012, p. 10. Recuperado el 7 de octubre de 2015, de http://www.europarl.europa.eu/sides/getDoc.do?pubRef=//EP//NONSGML+REPORT+A7-2012-0284+0+DOC+PDF+V0//ES.

${ }^{23}$ PARLAMENTO EUROPEO, Proyecto de informe sobre las repercusiones medioambientales de la extracción de gas y petróleo de Esquisto, 2011/2308(INI), 25 de septiembre de 2012, p. 18. Recuperado el 7 de octubre de 2015, de http://www.europarl.europa.eu/sides/getDoc.do?pubRef=//EP//NONSGML+REPORT+A7-2012-0283+0+DOC+PDF+V0//ES.

${ }^{24}$ COMISIÓN EUROPEA, Comunicación sobre la exploración... cit., pp. 4-5.

${ }^{25}$ COMISIÓN EUROPEA, Recomendación de la Comisión Europea relativa a unos principios mínimos para la exploración y producción de hidrocarburos (como el gas de esquisto) utilizando la fracturación hidráulica de alto volumen, 22 de enero de 2014, p. 74. Recuperado el 7 de octubre de 2015, de http://eurlex.europa.eu/LexUriServ/LexUriServ.do?uri=OJ:L:2014:039:0072:0078:ES:PDF.

${ }^{26}$ MOREU, E., "Marco jurídico de la extracción de hidrocarburos mediante fractura hidráulica (fracking)", Revista Catalana de Dret Ambiental, 2012, pp. 10-13.

${ }^{27}$ BLASCO, E., Recomendación de la Comisión de 22 de enero de 2014 relativa a unos principios mínimos para la exploración y producción de hidrocarburos (como el gas de esquisto) utilizando la fracturación hidráulica de alto volumen. (L 39/72 DOUE 8.2.2014). Recuperado el 23 de abril de 2016, de http://www.actualidadjuridicaambiental.com/legislacion-al-dia-union-europea-fractura-hidraulica/. 


\section{MARCO JURÍDICO DE LA EXTRACCIÓN DE HIDROCARBUROS MEDIANTE FRACTURA HIDRÁULICA A NIVEL ESPAÑOL}

España, a día de hoy, no posee reservas importantes de hidrocarburos convencionales. Se estima, empero, que las reservas de gas de esquisto podrían ser significativas ${ }^{28}$. Así, en esta tesitura, a pesar de que en la actualidad no existe ninguna explotación comercial, el posicionamiento adoptado por el Gobierno central es claramente favorable a la fractura hidráulica.

No obstante, la postura del Gobierno central difiere de la adoptada por algunas comunidades autónomas. Las comunidades autónomas de Cantabria, La Rioja, Navarra, Cataluña y País Vasco han elaborado leyes que prohíben, de manera absoluta en el caso de las tres primeras y en determinados casos y bajo determinadas circunstancias en el caso de las dos últimas, el fracking en sus territorios. Todas estas leyes han sido objeto de un recurso de inconstitucionalidad por parte del Gobierno central (véase tabla 1).

Tabla 1: Leyes promovidas por distintas comunidades autónomas que prohíben el fracking

\begin{tabular}{|c|c|}
\hline $\begin{array}{l}\text { Comunidad } \\
\text { Autónoma }\end{array}$ & Leyes que prohíben el fracking en su territorio \\
\hline CANTABRIA & $\begin{array}{l}\text { LEY: Ley } 1 / 2013 \text {, de } 15 \text { de abril, por la que se regula la prohibición en el } \\
\text { territorio de la Comunidad Autónoma de Cantabria de la técnica de fractura } \\
\text { hidráulica como técnica de investigación y extracción de gas no convencional }{ }^{29} \text {. } \\
\text { SITUACIÓN ACTUAL: Recurso de inconstitucionalidad interpuesto por el } \\
\text { presidente del Gobierno el } 27 \text { de enero de } 2014 \text {, que fue admitido a trámite por el } \\
\text { Tribunal Constitucional mediante providencia de } 11 \text { de febrero de } 2014^{30} \text {. Ley } \\
\text { declarada inconstitucional por la STC } 106 / 2014 \text {, de } 24 \text { de junio }{ }^{31} \text {. }\end{array}$ \\
\hline
\end{tabular}

\footnotetext{
${ }^{28}$ AYLLÓN, "El agua..." cit., p. 37.

${ }^{29}$ BOE, núm. 111, de 9 de mayo de 2013. Recuperado el 9 de octubre de 2015, de https://www.boe.es/boe/dias/2013/05/09/pdfs/BOE-A-2013-4828.pdf.

${ }^{30}$ BOE, núm. 40, de 15 de febrero de 2014. Recuperado el 9 de octubre de 2015, de https://www.boe.es/boe/dias/2014/02/15/pdfs/BOE-A-2014-1633.pdf.

${ }^{31}$ BOE, núm. 177, de 22 de julio de 2014. Recuperado el 9 de octubre de 2015, de https://www.boe.es/boe/dias/2014/07/22/pdfs/BOE-A-2014-7787.pdf.
} 


\begin{tabular}{|c|c|}
\hline LA RIOJA & $\begin{array}{l}\text { LEY: Ley } 7 / 2013 \text {, de } 21 \text { de junio, por la que se regula la prohibición en el } \\
\text { territorio de la Comunidad Autónoma de La Rioja de la técnica de la fractura } \\
\text { hidráulica como técnica de investigación y extracción de gas no convencional }{ }^{32} \text {. } \\
\text { SITUACIÓN ACTUAL: Recurso de inconstitucionalidad interpuesto por el } \\
\text { presidente del Gobierno el } 24 \text { de marzo de } 2014 \text {, que fue admitido a trámite por el } \\
\text { Tribunal Constitucional mediante providencia de } 8 \text { de abril de } 2014^{33} \text {. Ley } \\
\text { declarada inconstitucional por la STC } 134 / 2014 \text {, de } 22 \text { de julio }{ }^{34} \text {. }\end{array}$ \\
\hline NAVARRA & $\begin{array}{l}\text { LEY: Ley Foral 30/2013, de } 15 \text { de octubre, por la que se prohíbe en el territorio } \\
\text { de la Comunidad Foral de Navarra el uso de la fractura hidráulica como técnica } \\
\text { de investigación y extracción de gas no convencional }{ }^{35} \text {. } \\
\text { SITUACIÓN ACTUAL: Recurso de inconstitucionalidad interpuesto por el } \\
\text { presidente del Gobierno el } 28 \text { de julio de } 2014 \text {, que fue admitido a trámite por el } \\
\text { Tribunal Constitucional mediante providencia de } 9 \text { de septiembre de } 2014^{36} \text {. Ley } \\
\text { declarada inconstitucional por la STC } 208 / 2014 \text {, de } 15 \text { de diciembre de } 2014^{37} \text {. }\end{array}$ \\
\hline CATALUÑA & $\begin{array}{l}\text { LEY: Ley } 2 / 2014 \text {, de } 27 \text { de enero, de medidas fiscales, administrativas, } \\
\text { financieras y del sector público }{ }^{38} \text {. } \\
\text { SITUACIÓN ACTUAL: Recurso de inconstitucionalidad interpuesto por el } \\
\text { presidente del Gobierno el } 30 \text { de octubre de } 2014 \text {, que fue admitido a trámite por } \\
\text { el Tribunal Constitucional mediante providencia de } 18 \text { de noviembre de } 2014^{39} \text {. } \\
\text { El Tribunal Constitucional levantó la suspensión aplicada el } 18 \text { de noviembre de } \\
2014 \text { sobre el artículo } 167.1 \text { de la Ley } 2 / 2014 \text { de Cataluña, por el que se prohibía } \\
\text { la técnica de fractura hidráulica para la extracción de hidrocarburos no } \\
\text { convencionales en Cataluña }{ }^{40} \text {. Pero, recientemente, el } 25 \text { de abril de } 2016 \text {, ha }\end{array}$ \\
\hline
\end{tabular}

${ }^{32}$ BOE, núm. 163, de 9 de julio de 2013. Recuperado el 9 de octubre de 2015, de https://www.boe.es/boe/dias/2013/07/09/pdfs/BOE-A-2013-7480.pdf.

${ }^{33}$ BOE, núm. 89, de 12 de abril de 2014. Recuperado el 9 de octubre de 2015, de https://www.boe.es/boe/dias/2014/04/12/pdfs/BOE-A-2014-3947.pdf.

${ }^{34}$ BOE, núm. 199, de 16 de agosto de 2014. Recuperado el 9 de octubre de 2015, de https://www.boe.es/boe/dias/2014/08/16/pdfs/BOE-A-2014-8767.pdf.

${ }^{35}$ BON, núm. 208, de 28 de octubre de 2013. Recuperado el 9 de octubre de 2015, de http://www.lexnavarra.navarra.es/detalle.asp?r=32713.

${ }^{36}$ BOE, núm. 223, de 13 de septiembre de 2014. Recuperado el 9 de octubre de 2015, de https://www.boe.es/boe/dias/2014/09/13/pdfs/BOE-A-2014-9328.pdf.

${ }^{37}$ BOE, núm. 17, de 20 de enero de 2015. Recuperado el 9 de octubre de 2015, de http://www.boe.es/boe/dias/2015/01/20/pdfs/BOE-A-2015-465.pdf.

${ }^{38}$ BOE, núm. 69, de 21 de marzo de 2014. Recuperado el 9 de octubre de 2015, de https://www.boe.es/boe/dias/2014/03/21/pdfs/BOE-A-2014-2999.pdf.

${ }^{39}$ BOE, núm. 281, de 20 de noviembre de 2014. Recuperado el 9 de octubre de 2015, de https://www.boe.es/boe/dias/2014/11/20/pdfs/BOE-A-2014-11986.pdf.

${ }^{40}$ BOE, núm. 74, de 27 de marzo de 2015. Recuperado el 9 de octubre de 2015, de https://www.boe.es/boe/dias/2015/03/27/pdfs/BOE-A-2015-3273.pdf. 


\begin{tabular}{|c|c|}
\hline & $\begin{array}{l}\text { dado a conocer la sentencia que declara la inconstitucionalidad de la Ley catalana, } \\
\text { al considerar que esta "da pie a una interpretación manifiestamente contraria a la } \\
\text { legislación básica estatal" pues el fracking "queda prohibido con carácter absoluto } \\
\text { en el territorio de Cataluña siempre que su utilización concierna cualquier 'ámbito } \\
\text { competencial' de la Generalitat"41. }\end{array}$ \\
\hline ANDALUCÍA & $\begin{array}{l}\text { PROPOSICIÓN DE LEY: Proposición de Ley por la que se regula la utilización } \\
\text { de la técnica de la fractura hidráulica como técnica de investigación y extracción } \\
\text { de gas no convencional en la Comunidad Autónoma de Andalucía, admitida a } \\
\text { trámite por la Mesa del Parlamento el } 4 \text { de septiembre de } 2014^{42} \text { y tomada en } \\
\text { consideración por el Pleno el } 10 \text { de diciembre de } 2014^{43} \text {. } \\
\text { SITUACIÓN ACTUAL: El } 26 \text { de enero de } 2015 \text { se disuelve la Cámara y se } \\
\text { anuncia la convocatoria de elecciones en Andalucía, que se celebran el } 22 \text { de } \\
\text { marzo de } 2015 \text {. Con ello, decae la Proposición de Ley. }\end{array}$ \\
\hline PAÍS VASCO & $\begin{array}{l}\text { LEY: Ley } 6 / 2015 \text {, de } 30 \text { de junio, de medidas adicionales de protección } \\
\text { medioambiental para la extracción de hidrocarburos no convencionales y la } \\
\text { fractura hidráulica o fracking }{ }^{44} \text {. } \\
\text { SITUACIÓN ACTUAL: Recurso de inconstitucionalidad interpuesto por el } \\
\text { Gobierno en funciones el } 8 \text { de abril de } 2016^{45} \text {. }\end{array}$ \\
\hline
\end{tabular}

Fuente: elaboración propia

A pesar del rechazo a la utilización de la técnica del fracking en su territorio mostrado por algunas comunidades autónomas a través de leyes o propuestas de ley, se observa que, en mayor o menor medida, todas ellas han encontrado la clara oposición del Gobierno central. Asimismo, de las leyes cántabra, riojana y navarra se infiere que las

\footnotetext{
${ }^{41}$ TRIBUNAL CONSTITUCIONAL, E1 TC declara inconstitucional la Ley que prohíbe el "fracking” en Cataluña. Recuperado el 1 de mayo de 2016, de http://www.tribunalconstitucional.es/es/salaPrensa/Documents/NP_2016_034/Nota\%20Informativa\%20n \%C2\%BA\%2034-2016.pdf.

${ }^{42}$ BOPA, núm. 517, de 10 de septiembre de 2014. Recuperado el 9 de octubre de 2015, de http://www.parlamentodeandalucia.es/webdinamica/portal-webparlamento/pdf.do?tipodoc $=$ bopa\&id $=95593$.

${ }^{43}$ BOPA, núm. 586, de 18 de diciembre de 2014. Recuperado el 9 de octubre de 2015, de http://www.parlamentodeandalucia.es/webdinamica/portal-webparlamento/pdf.do?tipodoc=bopa\&id $=100013$.

${ }^{44}$ BOE, núm. 176, de 24 de julio de 2015. Recuperado el 9 de octubre de 2015, de https://www.boe.es/boe/dias/2015/07/24/pdfs/BOE-A-2015-8274.pdf.

${ }^{45}$ LA MONCLOA, GOBIERNO DE ESPAÑA, Recurso de inconstitucionalidad contra la Ley del País Vasco de medidas de protección medioambiental ante la fractura hidráulica, Consejo de Ministros de 8 de abril de 2016. Recuperado el 24 de abril de 2016, de http://www.lamoncloa.gob.es/consejodeministros/referencias/Paginas/2016/refc20160408.aspx.
} 
comunidades autónomas no pueden establecer una prohibición absoluta de la fractura hidráulica sin contravenir la vigente legislación básica española.

A continuación, por una parte, se indican las distintas normativas españolas que afectan de manera significativa a la exploración, investigación y explotación de gas no convencional, y, por otra, se señala la doctrina establecida por el Tribunal Constitucional en torno al fracking.

\section{Sumario de las competencias del Estado en la materia}

Los principales ámbitos competenciales en juego son la ordenación del territorio, la ordenación de materias energéticas y la protección medioambiental ${ }^{46}$.

Como señala el profesor Fernández de $\mathrm{Gatta}^{47,48}$, la Constitución Española (CE, en adelante) otorga al Estado la competencia exclusiva en materia de "bases de régimen minero y energético" (art. 149.1.25 $\mathrm{CE}$ ) ${ }^{49}$. El concepto de legislación o normativa básica incluye una acepción material (SSTC 170/1989, de 19 de octubre, 102/1995, de 26 de junio, 306/2000, de 12 de diciembre, 166/2002, de 18 de septiembre, y 146/2013, de 11 de julio) ${ }^{50}$ y otra formal (SSTC 149/1991, de 4 de julio, y 102/1995, de 26 de junio, remitiéndose a la STC 329/1993, de 12 de noviembre) ${ }^{51}$. Mediante la legislación básica, pues, el Estado establece un tratamiento común con independencia de la parte

\footnotetext{
${ }^{46}$ PÉREZ DE AYALA, L. y ANTÓN, D., "Sobre la constitucionalidad de un anteproyecto de ley autonómica que contempla la prohibición absoluta de la actividad de extracción de gas no convencional en el territorio de una comunidad autónoma", Recuerda Girela, M. A. (coord.), Problemas prácticos y actualidad del Derecho administrativo, Civitas, 2014, p 332.

${ }^{47}$ FERNÁNDEZ DE GATTA, D., “Aportaciones jurídicas al debate sobre la obtención de gas no convencional mediante la técnica de fractura hidráulica”, Diario La Ley, 2014, pp. 10-11.

${ }^{48}$ FERNÁNDEZ DE GATTA, D., "Regulación de la obtención de gas no convencional mediante la técnica de fractura hidráulica: situación en la Unión Europea y en España”, Revista Vasca de Administración Pública, 2014, pp. 1344-1346.

${ }^{49}$ CONSTITUCIÓN ESPAÑOLA, título VIII, "De la Organización Territorial del Estado”, capítulo tercero, "De las Comunidades Autónomas". Recuperado el 14 de mayo de 2016, de http://www.congreso.es/consti/constitucion/indice/titulos/articulos.jsp?ini=143\&fin=158\&tipo=2.

${ }^{50}$ STCs 170/1989, 102/1995, 306/2000, 166/2002, 146/2013. Recuperado el 14 de mayo de 2016, de https://www.boe.es/boe/dias/1989/11/07/pdfs/T00049-00056.pdf, https://www.boe.es/boe/dias/1995/07/31/pdfs/T00003-00044.pdf, https://www.boe.es/boe/dias/2001/01/16/pdfs/T00079-00093.pdf, https://www.boe.es/boe/dias/2002/10/09/pdfs/T00057-00063.pdf, https://www.boe.es/boe/dias/2013/08/01/pdfs/BOE-A-2013-8504.pdf.

${ }^{51}$ STCs 149/1991, 102/1995, 329/1993. Recuperado el 14 de mayo de 2016, de https://www.boe.es/boe/dias/1991/07/29/pdfs/T00014-00053.pdf, https://www.boe.es/boe/dias/1995/07/31/pdfs/T00003-00044.pdf, https://www.boe.es/boe/dias/1993/12/10/pdfs/T00032-00038.pdf.
} 
del territorio español en el que se quiera realizar una determinada actividad, siendo dicha normativa de aplicación en toda España, tal como señalan con claridad, en unos asuntos sobre la competencia nacional en materia de hidrocarburos (en concreto, petróleo), las SSTC 24/1985, de 21 de febrero, y 197/1996, de 28 de noviembre ${ }^{52}$.

Por otro lado, siguiendo con lo indicado por el profesor Fernández de Gatta, a la misma conclusión llegan, teniendo en cuenta las competencias del Estado en materia de planificación general de la actividad económica y en materia minera y energética, las SSTC 223/2000, de 21 de septiembre (sobre distribución de gases licuados de petróleo), 18/2011, de 3 de marzo (sobre el sector eléctrico), y 135/2012, de 19 de junio (sobre el sector de hidrocarburos) ${ }^{53}$, y la STS de 10 de octubre de 2012 (rec. n. $76 / 2011$ ), sobre la producción de energía eléctrica en régimen especial ${ }^{54}$. Por lo tanto, de acuerdo con esta doctrina, parecía claro que, desde el punto de vista de la planificación de las actividades energéticas, no era posible constitucionalmente que una comunidad autónoma pudiera incumplir la legislación básica del Estado, sortearla u obviarla, y mucho menos prohibir algo que competencialmente no le correspondía, pues la prohibición de una actividad económica únicamente le correspondería adoptarla, en su caso, al Estado, al incidir la medida regional prohibitiva sobre ambos títulos competenciales. De hecho, en relación con una medida que prohibía actividades mineras en determinados suelos, la STS de 3 de noviembre de 2010 (rec. n. ${ }^{\text { }}$ 5294/2007) ${ }^{55}$ ya tuvo ocasión de anular un instrumento de ordenación del territorio de carácter reglamentario por invadir, precisamente, las competencias del Estado en materia minera.

\footnotetext{
${ }^{52}$ STCs 24/1985, 197/1996. Recuperado el 14 de mayo de 2016, de https://www.boe.es/boe/dias/1985/03/27/pdfs/T00001-00005.pdf, https://www.boe.es/boe/dias/1997/01/03/pdfs/T00070-00088.pdf.

${ }^{53}$ STCs 223/2000, 18/2011, 135/2012. Recuperado el 14 de mayo de 2016, de https://www.boe.es/boe/dias/2000/10/19/pdfs/T00059-00075.pdf, https://www.boe.es/boe/dias/2011/03/29/pdfs/BOE-A-2011-5704.pdf, https://www.boe.es/boe/dias/2012/07/09/pdfs/BOE-A-2012-9211.pdf.

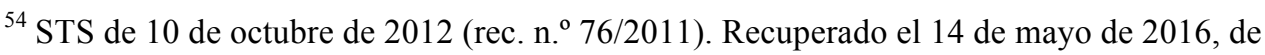
http://www.poderjudicial.es/search/doAction?action=contentpdf\&databasematch=TS\&reference $=652841$ 1\&links=producci\%C3\%B3n\%20de $\% 20$ energ\%C3\%ADa\%20el\%C3\%A9ctrica $\% 20$ en $\% 20 \mathrm{r} \% \mathrm{C} 3 \%$ A9gi men\%20especial\%20\%2276\%2F2011\%22\&optimize=20121105\&publicinterface=true.

${ }^{55}$ STS de 3 de noviembre de 2010 (rec. n. ${ }^{\circ}$ 5294/2007). Recuperado el 14 de mayo de 2016, de http://www.poderjudicial.es/search/doAction?action=contentpdf\&databasematch $=$ TS\&reference $=580494$ $9 \&$ links $=\% 225294 \% 2 \mathrm{~F} 2007 \% 22 \&$ optimize $=20101223 \&$ publicinterface $=$ true.
} 
Por último, el profesor Fernández de Gatta señala que, aunque la doctrina anterior es suficientemente clara, asimismo debe tenerse en cuenta que el Estado ostenta la competencia exclusiva sobre la legislación básica en materia de medio ambiente (art. 149.1.23 $\mathrm{CE})$.

Ahora bien, sin obviar la potestad autonómica de desarrollar normas adicionales de protección en materia medioambiental, es precisamente la ponderación entre la protección del medio ambiente y el desarrollo económico de un país, en este caso mediante el desarrollo de una actividad concreta de extracción de recursos energéticos, una de las claves a la hora de analizar el marco jurídico en el que puede actuar una comunidad autónoma al regular sobre esta materia.

En este sentido, el Tribunal Constitucional (STC 64/1982) ${ }^{56}$ establece que la regulación que se realice de una determinada actividad ha de integrar y armonizar dos principios: el del interés público presente en la actividad económica (en ese supuesto, la explotación de los yacimientos mineros, perfectamente extrapolable al que aquí nos ocupa), sin el que no es posible el desarrollo económico, y el de la preservación del medio ambiente.

Pérez de Ayala y Antón indican que ${ }^{57}$ el artículo 45 de la Constitución recoge la preocupación ecológica surgida en las últimas décadas en amplios sectores de opinión, preocupación plasmada también en numerosos documentos internacionales. En virtud de dicho artículo no puede considerarse como objetivo primordial y excluyente la explotación al máximo de los recursos naturales o el aumento de la producción a toda costa, sino que se ha de armonizar la "utilización racional" de esos recursos con la protección de la naturaleza, todo ello para un mejor desarrollo de las personas y para asegurar una mejor calidad de la vida. Estas consideraciones son aplicables tanto a las industrias extractivas como a cualquier otro sector económico y suponen, en consecuencia, que no es aceptable la postura del representante del Gobierno, repetida frecuentemente a lo largo de sus alegaciones, de que exista una prioridad absoluta del fomento de la producción minera frente a la protección del medio ambiente.

La sentencia mencionada admite restricciones autonómicas a las actividades extractivas siempre que estas cargas y requisitos no alteren el ordenamiento básico minero, sean razonables y proporcionadas al fin propuesto, y no quebranten el principio de

\footnotetext{
${ }^{56}$ BOE, núm. 296, de 10 de diciembre de 1982. Recuperado el 18 de mayo de 2016, de https://www.boe.es/boe/dias/1982/12/10/pdfs/T00001-00005.pdf.

${ }^{57}$ PÉREZ DE AYALA y ANTÓN, “Sobre la constitucionalidad...” cit., pp. 348-349.
} 
solidaridad $^{58}$. Habrá que analizar, a la luz de esos condicionantes, cualquier legislación autonómica que establezca restricciones a una actividad económica que pretenda investigar o explotar recursos energéticos mediante técnicas extractivas.

\section{Marco regulatorio de la exploración, investigación y explotación de gas no convencional en España}

Según la legislación española, los hidrocarburos (y entre ellos, los no convencionales) son propiedad del Estado, por lo que se requiere una concesión para extraerlos. Las reglas para otorgar las correspondientes autorizaciones de exploración, permisos de investigación y concesiones de explotación siguen las pautas fijadas en la Ley sobre el Régimen Jurídico de la Investigación y Exploración de los Hidrocarburos de 1958. Posteriormente se publicó la Ley 21/1974, de 27 de junio, sobre investigación y explotación de hidrocarburos ${ }^{59,60}$, derogada por la actual ley en vigor, la Ley 34/1998, de 7 de octubre ${ }^{61,62}$.

De esta forma, es obligado comenzar con una referencia a la Ley 34/1998, de 7 de octubre, del Sector de Hidrocarburos (LSH, en adelante), por ser la normativa que establece la regulación vertical del sector, es decir, desde la exploración y la producción de hidrocarburos hasta su refino y distribución ${ }^{63,}{ }^{64}$. Sin embargo, la LSH no mencionaba antes de 2013 en ningún artículo el empleo de la fracturación hidráulica en la exploración, investigación o explotación de hidrocarburos ${ }^{65}$.

\footnotetext{
${ }^{58}$ SANTAMARÍA, “Las claves..." cit., p. 21.

${ }^{59}$ BOE, núm. 155, de 29 de junio de 1974. Recuperado el 25 de abril de 2016, de https://www.boe.es/boe/dias/1974/06/29/pdfs/A13554-13564.pdf.

${ }^{60}$ La Ley 21/1974, de 27 de junio, fue desarrollada por el Real Decreto 2362/1976, de 30 de julio. BOE, núm. 247, de 14 de octubre de 1976. Recuperado el 27 de abril de 2016, de https://www.boe.es/boe/dias/1976/10/14/pdfs/A20027-20054.pdf.

${ }^{61}$ BOE, núm. 241, de 8 de octubre de 1998. Recuperado el 24 de abril de 2016, de https://www.boe.es/buscar/pdf/1998/BOE-A-1998-23284-consolidado.pdf.

${ }^{62}$ ÁLVAREZ, E. y SUÁREZ, C., Gas no convencional: shale gas. Aspectos estratégicos, técnicos, medioambientales y regulatorios, Orkestra - Instituto Vasco de Competitividad, 2014, p. 219.

${ }^{63}$ CONSEJO SUPERIOR DE COLEGIOS DE INGENIEROS DE MINAS, Gas no convencional en España, una oportunidad de futuro, p. 86. Recuperado el 24 de abril de 2016, de http://ingenierosdeminas.org/documentos/130312_informe_gas.pdf.

${ }^{64}$ BOQUERA, V. y JIMÉNEZ, J., “¿Puede el Fracking ser materia de acuerdo local?”, Cuadernos de Derecho Local (QDL), núm. 33, 2013, pp. 175-177.

${ }^{65}$ SÁNDEZ, J. D., "Fracturación hidráulica y Comunidades Autónomas: a propósito de dos proposiciones de ley presentadas en Andalucía”, Actualidad Jurídica Ambiental, 2015, p. 4.
} 
Con todo, la LSH fue modificada (incluyendo un nuevo apartado 5 al artículo 9) por la Ley 17/2013, de 29 de octubre, para la garantía del suministro e incremento de la competencia en los sistemas eléctricos insulares y extrapeninsulares ${ }^{66}$, a través de su disposición final segunda, para incluir la fracturación hidráulica como una de las técnicas que pueden ser empleadas en el desarrollo de los trabajos de exploración y, sobre todo, investigación y explotación de estos recursos ${ }^{67}$.

Asimismo, según la disposición final cuarta, "lo dispuesto en esta Ley tiene carácter básico al dictarse al amparo de las competencias que corresponden al Estado en el artículo 149.1.13. ${ }^{\mathrm{a}}$ y $25 .^{\mathrm{a}}$ de la Constitución Española, que atribuye al Estado la competencia exclusiva para determinar las bases y coordinación de la planificación general de la actividad económica y las bases del régimen minero y energético, respectivamente". Por lo tanto, a pesar de que la voluntad del legislador sea imponer la unidad de criterio, el carácter básico de la norma solo le permite, en principio, establecer un mínimo común denominador normativo que pueda ser objeto de desarrollo autonómico $^{68}$.

Además, la Ley 17/2013, de 29 de octubre, a través de su disposición final tercera, modificó el Real Decreto Legislativo 1/2008, de 11 de enero, por el que se aprueba el texto refundido de la Ley de Evaluación de Impacto Ambiental de proyectos ${ }^{69}$ (TRLEIA, en adelante) (se añade un nuevo párrafo e) al anexo I, grupo 2). Así, se determinó que la evaluación de impacto ambiental fuese obligatoria para "los proyectos consistentes en la realización de perforaciones para la exploración, investigación o explotación de hidrocarburos que requieran la utilización de técnicas de fracturación hidráulica”. Sin embargo, el TRLEIA fue derogado íntegramente por la Ley 21/2013, de 9 de diciembre, de Evaluación Ambiental ${ }^{70}$ (LEA, en adelante). Dicha Ley recoge en el anexo I, grupo 2, apartado d) que se someterán a evaluación de impacto ambiental "los proyectos consistentes en la realización de perforaciones para la exploración,

\footnotetext{
${ }^{66}$ BOE, núm. 260, de 30 de octubre de 2013. Recuperado el 24 de abril de 2016, de https://www.boe.es/buscar/pdf/2013/BOE-A-2013-11332-consolidado.pdf.

${ }^{67}$ ÁLVAREZ, M., "El aprovechamiento de hidrocarburos no convencionales mediante fracturación hidráulica", Revista General de Derecho Administrativo, 2014, p. 17.

${ }^{68}$ SANTAMARÍA, "Las claves...” cit., pp. 17-18.

${ }^{69}$ BOE, núm. 296, de 11 de diciembre de 2013. Recuperado el 10 de mayo de 2016, de https:/www.boe.es/boe/dias/2013/12/11/pdfs/BOE-A-2013-12913.pdf.

${ }^{70}$ BOE, núm. 296, de 11 de diciembre de 2013. Recuperado el 27 de abril de 2016, de https://www.boe.es/boe/dias/2013/12/11/pdfs/BOE-A-2013-12913.pdf.
} 
investigación o explotación de hidrocarburos, almacenamiento de $\mathrm{CO}_{2}$, almacenamiento de gas y geotermia de media y alta entalpía, que requieran la utilización de técnicas de fracturación hidráulica". Y se añade que "no se incluyen en este apartado las perforaciones de sondeos de investigación que tengan por objeto la toma de testigo previos a proyectos de perforación que requieran la utilización de técnicas de fracturación hidráulica”.

De este modo, se observa que la reacción del legislador estatal ante las primeras prohibiciones autonómicas llega con la Ley 17/2013, de 29 de octubre ${ }^{71}$. A pesar de que no se trata de una norma específica sobre el fracking, en el preámbulo de esta se reconoce que "los recursos de hidrocarburos no convencionales están siendo objeto de un intenso debate social durante los últimos meses. Este debate se está produciendo en diferentes países y, España, no es una excepción”.

\section{La doctrina del Tribunal Constitucional}

Desde un punto de vista jurídico, el Tribunal Constitucional marca el escenario de lo posible en tanto la legislación estatal no sea modificada. El debate de la posibilidad de prohibir el fracking mediante una ley autonómica ha sido cerrado por el momento ${ }^{72}$.

Las sentencias del Tribunal Constitucional que declararon inconstitucionales las leyes autonómicas de Cantabria, La Rioja y Navarra sobre la extracción de gas mediante la técnica de la fractura hidráulica son, respectivamente, la STC 106/2014, de 24 de junio, la STC 134/2014, de 22 de julio, y la STC 208/2014, de 15 de diciembre. Las leyes impugnadas establecían una prohibición absoluta del uso de esta técnica en sus territorios. El Tribunal Constitucional concluyó que dicha prohibición contradecía de manera radical e insalvable lo dispuesto con carácter de legislación básica en materia de régimen energético en el artículo 9.5 de la LSH y en la LEA, que permiten el uso de la técnica de la fractura hidráulica con sujeción a requisitos técnicos y a la exigencia de la previa declaración de impacto ambiental.

\footnotetext{
${ }^{71}$ SANTAMARÍA, “Las claves...” cit., p. 16.

${ }^{72}$ JORDANO, J., "El fracking en el estrado: Recogiendo el guante verde arrojado por el tribunal constitucional a las comunidades autónomas", Revista Aragonesa de Administración Pública, 2015, pp. 24-25.
} 
Pero merece la pena detenerse más detalladamente en la reciente sentencia del Tribunal Constitucional de 4 de abril de 2016, que ha estimado parcialmente el recurso de inconstitucionalidad presentado por el Gobierno contra la Ley 2/2014, de 27 de enero, de medidas fiscales, administrativas, financieras y del sector público de Cataluña. La sentencia declara nulo el artículo 167.1, que añadía un apartado 10 al artículo 47 del texto refundido de la Ley de Urbanismo de Cataluña ${ }^{73}$ (TRLUC, en adelante), aprobado por Decreto Legislativo 1/2010, de 3 de agosto, conforme al cual: "En la explotación de recursos naturales en suelo no urbanizable, en el caso de aprovechamiento de hidrocarburos, no está permitida la utilización de la tecnología de la fracturación hidráulica cuando pueda tener efectos negativos sobre las características geológicas, ambientales, paisajísticas o socioeconómicas de la zona, o en relación con otros ámbitos competenciales de la Generalitat".

Este artículo es similar, cuando no idéntico, al artículo 3 de la Ley vasca que posteriormente se analizará. De ahí la importancia del análisis más detallado de la solución dada por el Tribunal Constitucional. En esta ocasión, el Tribunal Constitucional, aunque los casos no son iguales, aplica la misma doctrina que en las sentencias relativas a las leyes autonómicas de Cantabria, La Rioja y Navarra, ya que, según el Tribunal, la norma catalana convierte en excepcional la posibilidad de utilizar la técnica de la fractura hidráulica y no precisa ni establece requisitos razonables y proporcionados con fines de protección medioambiental (especialmente relevantes en la argumentación de estos aspectos resultan los puntos 9 y 10 de los fundamentos jurídicos de la mencionada sentencia) $)^{74}$.

Esta sentencia cuenta con el voto particular del magistrado Juan Antonio Xiol Ríos, que también ha sido suscrito mediante otro voto particular conjunto por la magistrada Adela Asua Batarrita y el magistrado Fernando Valdés Dal-Ré. Ese voto particular discrepa de la sentencia no solo por la metodología del análisis en el que se sustenta la opinión mayoritaria (cabe recordar que en la STC 106/2014 los mismos magistrados ya formularon un voto particular, aunque en aquella ocasión no discrepante sino

\footnotetext{
${ }^{73}$ BOE, núm. 218, de 8 de septiembre de 2010. Recuperado el 28 de abril de 2016, de https://www.boe.es/boe/dias/2010/09/08/pdfs/BOE-A-2010-13883.pdf.

${ }^{74}$ TRIBUNAL CONSTITUCIONAL, E1 TC declara inconstitucional la Ley que prohíbe el "fracking” en Cataluña. Recuperado el 28 de abril de 2016, de http://www.tribunalconstitucional.es/es/salaPrensa/Documents/NP_2016_034/2014-06513STC.pdf.
} 
concurrente, ya que no cuestionaba el fallo), sino también por el enfoque dado a la cuestión para llegar al fallo. En esta ocasión también discrepa del fallo.

De una manera sucinta, el punto 8 del voto particular expone las razones de la discrepancia, al considerar el magistrado que el precepto impugnado no invade competencias estatales básicas ya que, proyectando un juicio de proporcionalidad propio de los supuestos de concurrencia competencial, (i) los criterios establecidos responden a intereses constitucionales dignos de protección que, siendo competencia de la comunidad autónoma, deben ser ponderados con los intereses generales de carácter básico en materia energética; (ii) no provocan un vacío de la competencia estatal básica de regulación del uso de esa técnica; (iii) no resultan contradictorios con la normativa básica estatal ni en cuanto al ámbito de discrecionalidad que proyectan ni en cuanto a su ámbito objetivo; y (iv) son especialmente relevantes y dignos de protección desde la perspectiva del Estado social de derecho ${ }^{75}$.

\section{MARCO JURÍDICO DE LA EXTRACCIÓN DE HIDROCARBUROS MEDIANTE FRACTURA HIDRÁULICA: REFLEXIONES SOBRE EL CASO DE LA COMUNIDAD AUTÓNOMA DEL PAÍS VASCO}

Respecto a la Comunidad Autónoma del País Vasco (CAPV), el artículo 17.4 de la Ley 16/1994, de 30 de junio, de Conservación de la Naturaleza del País Vasco ${ }^{76}$, que fue añadido por la Ley 1/2010, de 11 de marzo, de modificación de la Ley 16/1994, de 30 de junio, de Conservación de la Naturaleza del País Vasco ${ }^{77}$, se señalaba lo siguiente: "Dentro de los límites y zonas de afección de los espacios naturales protegidos no podrá llevarse a cabo explotación minera alguna, ni a cielo abierto ni de forma subterránea". Por lo tanto, en el caso de la CAPV se parte de una situación en la que existe una prohibición genérica que afecta a todo tipo de actividades extractivas, pero que, al

\footnotetext{
75 TRIBUNAL CONSTITUCIONAL, E1 TC declara inconstitucional la Ley que prohíbe el "fracking" en Cataluña. Voto particular. Recuperado el 28 de abril de 2016, de http://www.tribunalconstitucional.es/es/salaPrensa/Documents/NP_2016_034/2014-06513VPS.pdf.

${ }^{76}$ BOPV, núm. 142, de 27 de julio de 1994. Recuperado el 17 de enero de 2016, de http://www.euskadi.eus/bopv2/datos/1994/07/9402695a.pdf.

${ }^{77}$ BOE, núm. 93, de 17 de abril de 2010. Recuperado el 17 de enero de 2016, de https://www.boe.es/boe/dias/2010/04/17/pdfs/BOE-A-2010-6104.pdf.
} 
mismo tiempo, es también parcial puesto que solo rige en espacios naturales $\operatorname{protegidos}^{78}$.

Así, en octubre de 2011, el por aquel entonces lendakari Patxi López (PSE-EE), tras un viaje al campo de extracción de gas natural no convencional que la compañía Devon Energy Corporation tiene en Dallas (Texas, EE. UU.) ${ }^{79}$, anunció una gran apuesta por la extracción de hidrocarburos mediante fractura hidráulica en la CAPV. Esta apuesta energética encontró una especial oposición social en el territorio histórico de Álava debido, sobre todo, a la existencia de una gran cantidad de formaciones geológicas con indicios de que podían ser explotables mediante la técnica del fracking ${ }^{80,81}$.

En esta tesitura, a instancias de las Juntas Generales de Álava (órgano representativo y legislativo del territorio histórico de Álava con capacidad de presentar propuestas de ley al legislativo autonómico), el Parlamento autonómico admitió a trámite el 5 de diciembre de 2012 una proposición de ley ${ }^{82}$ que proponía mantener la redacción del artículo 17.4 y añadirle el siguiente texto: "De igual manera, queda prohibida la exploración y explotación de hidrocarburos mediante la técnica de la fracturación hidráulica o fracking". No obstante, la propuesta, pese a ser admitida a trámite por el pleno del Parlamento, se alejó por completo de sus objetivos iniciales tras el debate y proceso parlamentario, y dio como resultado el texto finalmente aprobado, la Ley 2/2013, de 10 de octubre, de modificación de la Ley 16/1994, de 30 de junio, de

\footnotetext{
${ }^{78}$ SANTAMARÍA, “Las claves..." cit., p. 12.

${ }^{79}$ En octubre de 2011, aprovechando un viaje oficial a Texas (una de las cunas de la fractura hidráulica), el entonces lendakari Patxi López aseguró que cerca de Vitoria existe un descomunal yacimiento de gas a 2.000 metros de profundidad que podría satisfacer las necesidades energéticas de la CAPV durante 60 años. Un goloso hallazgo al que, aseguró, nadie se había planteado llegar hasta ese momento ante la falta de una técnica adecuada. El Gobierno Vasco se alió con dos empresas norteamericanas e inició un proceso burocrático previo que aún sigue a medias (El Correo, 19/12/2014).

${ }^{80}$ SANTAMARÍA, “Las claves...” cit., p. 12.

${ }^{81}$ FRACKING EZ ARABA, “¿Por qué en Araba?”, Fracking Ez Araba (dir.), Fracking, una apuesta peligrosa, Vitoria-Gasteiz, 2012, pp. 78.

82 PARLAMENTO VASCO, Proposición de Ley "De modificación de la Ley 16/1994, de 30 de junio, de Conservación de la Naturaleza del País Vasco” (10\09\02\03\0001). Recuperado el 9 de febrero de 2016, de

http://www.legebiltzarra.eus/fr iniciac/DDW?W $=$ ini seccion $=9+$ and + ini serie $=2+$ and + ini sserie $=3+$ and +ini_legis $=10+$ and + ini_falta $=20120101: 20121231+$ and + ini_propocv $=\%$ 27JUNTAS+GENERALES+DE +ALAVA\%27+order+by+ini_numexp.
} 
Conservación de la Naturaleza del País Vasco ${ }^{83}$. Se excluyó de la nueva redacción del artículo 17.4 cualquier referencia al fracking, y, según la nueva Ley modificada:

Dentro de los límites de los espacios naturales protegidos y sus zonas de afección se prohibirán las actividades extractivas que resulten incompatibles con los valores ambientales que se protegen. Serán los instrumentos de planificación y/o gestión de cada espacio natural protegido los que determinen dicha incompatibilidad, motivando adecuadamente la incompatibilidad de las actividades con los valores medioambientales y los criterios de protección de dichos espacios y de sus zonas de afección. En todo caso, en los supuestos en los que estas actividades puedan ser compatibles con los valores ambientales que se protegen, los proyectos para actividades extractivas en espacios naturales protegidos se someterán en su integridad, tanto las labores extractivas propiamente dichas como las instalaciones previstas, a la preceptiva evaluación de impacto ambiental individualizada, la cual incluirá todos los trabajos necesarios para la reposición a la situación anterior y la recuperación de los valores ambientales preexistentes.

El Parlamento Vasco, el 10 de octubre de 2013, asumía la doctrina que sostiene que prohibir el fracking o cualquier otra actividad perjudicial para el medio ambiente en espacios protegidos contraviene la jurisprudencia del Tribunal Constitucional sobre la ilegalidad del establecimiento de prohibiciones genéricas de usos y actividades amparadas en la protección del medio ambiente. La modificación de la Ley de Conservación de la Naturaleza delegó, por lo tanto, en los instrumentos de ordenación y gestión de cada espacio protegido la decisión de prohibir proyectos concretos si perjudican al entorno ${ }^{84}$.

Así, el expediente de la Proposición de Ley propuesta por las Juntas Generales quedaba cerrado sin haber logrado su objetivo fundamental; se abría entonces el camino a la iniciativa legislativa popular (ILP) promovida por la plataforma Fracking Ez Araba ${ }^{85}$.

\footnotetext{
${ }^{83}$ BOE, núm. 271, de 12 de noviembre de 2013. Recuperado el 9 de febrero de 2016, de https://www.boe.es/boe/dias/2013/11/12/pdfs/BOE-A-2013-11798.pdf.

${ }^{84}$ DIEZ, T., "La ILP contra el "fracking" vuelve hoy al Parlamento", Diario de noticias de Álava $(19 / 12 / 2013)$.

${ }^{85}$ La plataforma o movimiento social Fracking Ez Araba (frackingez.org), que comienza su andadura a finales del 2011, nace con el objetivo principal de informar sobre la extracción de hidrocarburos mediante fractura hidráulica y generar un debate sobre dicha cuestión en la sociedad.
} 


\section{Iniciativa legislativa popular para prohibir la fractura hidráulica en la}

\section{Comunidad Autónoma del País Vasco}

El 31 de enero de 2013 la plataforma Fracking Ez Araba presentó una ILP $^{86}$ en la Cámara autonómica, conforme al artículo 27.4 del Estatuto de Autonomía del País Vasco $(E A P V)^{87}$ y de acuerdo con lo dispuesto en la Ley 8/1986, de 26 de junio, de Iniciativa Legislativa Popular ${ }^{88}$. El objetivo de dicha ILP era regular la extracción de hidrocarburos no convencionales y la fractura hidráulica o fracking. Sin embargo, la tramitación de la ILP no fue aceptada. La propuesta no prosperó al oponerse la mayoría de la Cámara (PSE-EE, PP y $\mathrm{PNV}^{89}$ ) bajo el argumento de que en ese momento se estaba tramitando una propuesta similar. Tal y como se ha recogido en el punto precedente, a petición de las Juntas Generales de Álava se solicitaba, a través de una proposición de ley, prohibir el fracking en espacios naturales protegidos mediante la reforma de la Ley 16/1994, de 30 de junio, de Conservación de la Naturaleza del País Vasco. La Mesa del Parlamento (órgano que gestiona la actividad parlamentaria) consideró que ambas iniciativas eran similares, por lo que la iniciativa promovida por Fracking Ez Araba no fue admitida a trámite por la interpretación, cuando menos dudosa, del reglamento de la Cámara vasca ${ }^{90}$.

Sin embargo, como ya se ha señalado anteriormente, el 10 de octubre de 2013 el expediente de la iniciativa presentada por las Juntas Generales de Álava quedaba

\footnotetext{
${ }^{86}$ PARLAMENTO VASCO, Proposición de Ley "Para la regulación de la extracción de hidrocarburos no

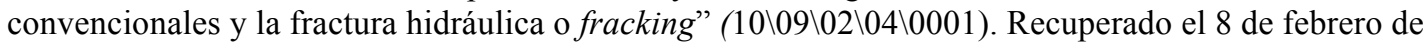
2016, de http://www.legebiltzarra.eus/fr iniciac/DDW?W=ini seccion $=9+$ and + ini serie $=2+$ and + ini sserie $=4+$ and +ini_legis $=10+$ and $+\% 28$ ini_fbaja+ne+null+or+ini_pendi $=0 \% 29+$ order+by+ini_numexp.

${ }^{87}$ BOE, núm. 306, de 18 de diciembre de 1979. Recuperado el 24 de febrero de 2016, de https://www.boe.es/buscar/pdf/1979/BOE-A-1979-30177-consolidado.pdf.

${ }^{88}$ BOE, núm. 77, de 30 de marzo de 2012. Recuperado el 24 de febrero de 2016, de https://www.boe.es/boe/dias/2012/03/30/pdfs/BOE-A-2012-4379.pdf.

${ }^{89}$ A pesar de que en el presente trabajo se utilizan los nombres de los partidos políticos, es preciso señalar cuál es el nombre que estos adoptan como grupos parlamentarios en el Parlamento Vasco:
}

- $\quad$ El Partido Nacionalista Vasco (PNV) se denomina Euzko Abertzaleak - Nacionalistas Vascos.

- El Partido Socialista de Euskadi-Euskadiko Ezkerra (PSE-EE) se denomina Socialistas Vascos Euskal Sozialistak. Popularra.

- El grupo parlamentario de EH Bildu adopta la denominación de Euskal Herria Bildu.

${ }^{90}$ EUROPA PRESS, "Fracking Ez Araba dice que el rechazo a su iniciativa es "una decisión política" que supone un "veto democrático", 20 Minutos (06/02/2016). 
cerrado. Al desaparecer así el obstáculo argüido por la Mesa del Parlamento, la ILP promovida por la plataforma Fracking Ez Araba volvía a abrirse camino en la Cámara autonómica.

Así, la plataforma Fracking Ez Araba registró el 19 de diciembre de 2013 una nueva ILP $^{91}$ para prohibir el uso de la fracturación hidráulica como método de extracción de gas del subsuelo en los tres territorios de la CAPV. El nuevo texto, que apenas difería del presentado anteriormente, tenía un carácter más proteccionista que la Proposición de Ley de las Juntas Generales de Álava y pretendía impedir el fracking no solo en los espacios naturales, sino también en toda la CAPV, además de regular el conjunto de los recursos no convencionales.

La Mesa del Parlamento admitió, ahora sí, la ILP a trámite. Por lo tanto, superado el primer trámite parlamentario en la Mesa del Parlamento, el siguiente requisito era recoger 30.000 firmas con validez legal en forma de apoyos a la Ley, contando para ello con un plazo de cuatro meses (ampliable a dos más). De esta manera, la ILP continuaría su trámite parlamentario como cualquier ley presentada por los grupos parlamentarios o el Gobierno autonómico. Superado el plazo, la iniciativa llegó avalada por 103.589 firmas.

En la sesión que debía tomar o no en consideración la tramitación de la ILP, todos los grupos parlamentarios votaron a favor de que esta continuara su procedimiento parlamentario. Así, en la sesión plenaria del 4 de diciembre de 2014, el Parlamento Vasco acuerda por unanimidad abrir el proceso de debate de la ILP contra el fracking.

La discusión parlamentaria sobre la ILP se desarrolló en la Comisión de Medio Ambiente, tal y como reivindicaban los proponentes de la iniciativa, y no, como había solicitado el PNV con el apoyo del PP, en la Comisión de Desarrollo Económico y Competitividad.

\section{2. "Triple filtro legal" contra el fracking}

\footnotetext{
${ }^{91}$ PARLAMENTO VASCO, Proposición de Ley "De medidas adicionales de protección medioambiental para la extracción de hidrocarburos no convencionales y la fractura hidráulica o "fracking"

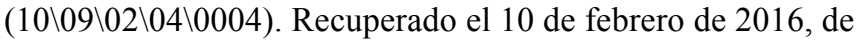
http://www.legebiltzarra.eus/fr_iniciac/DDW?W=ini_seccion $=9+$ and + ini_serie $=2+$ and + ini_sserie $=4+$ and + ini_legis $=10+$ and $+\% 28$ ini_fbaja+ne+null+or+ini_pendi $=0 \% 29+$ order+by+ini_numexp.
} 
A día de hoy, el Tribunal Constitucional ha anulado las leyes de Cantabria, La Rioja, Navarra y Cataluña que prohibían el fracking en su territorio (véase tabla 1) alegando para ello el carácter básico de la normativa estatal. Según el Tribunal, las leyes autonómicas citadas vulnerarían los títulos competenciales exclusivos a favor del Estado recogidos en los artículos $149.1 .13^{\mathrm{a}} \mathrm{CE}$, relativo a las bases y la coordinación de la planificación general de la actividad económica, y 149.1.25 $\mathrm{CE}$, relativo a las bases del régimen minero y energético.

Además, el Estado invoca los artículos 128.1 CE ("Toda la riqueza del país en sus distintas formas y sea cual fuere su titularidad está subordinada al interés general") y 130.1 CE (“[...] los poderes públicos atenderán a la modernización y desarrollo de todos los sectores económicos"), que considera igualmente vulnerados ${ }^{92}$.

Con la ILP inmersa en el proceso parlamentario, el colectivo promotor de la Propuesta de Ley es consciente de que debe superar al menos dos escollos para ver colmadas sus aspiraciones: que la Ley sea aprobada u obtenga el suficiente apoyo político; y que sea aplicable y efectiva en su puesta en práctica legal. Ambos escollos influyen directamente en la tramitación de la Propuesta de Ley y, de hecho, están relacionados. Por una parte, durante el tiempo que transcurre entre el registro de la ILP, el visto bueno dado por la Mesa del Parlamento Vasco y el primer posicionamiento político de los partidos en el pleno en el que la propuesta se admite a trámite, se suceden las manifestaciones políticas y los posicionamientos de los partidos con representación en la Cámara, con mayor o menor contundencia, en torno al empleo de la fractura hidráulica. La presión social continuaba siendo necesaria para continuar recabando apoyos políticos en torno a la esencia de la ILP y para que esta fuera aprobada. Por otra, dentro del contexto legislativo y como segundo obstáculo a superar, se encontraban las sentencias contra las leyes aprobadas por otras comunidades autónomas (Cantabria, La Rioja y Navarra).

Para evitar la amenaza objetiva del recurso y la suspensión automática por parte del Gobierno del Estado y del Tribunal Constitucional, se constata la necesidad de modificar y mejorar la propia Propuesta de Ley original. Para ello, se decide recurrir a la ingeniería legislativa y buscar la manera de que los probables recursos que pueda interponer el Estado resulten infructuosos. En definitiva, se decide articular un nuevo

\footnotetext{
${ }^{92}$ SERRANO, M., La regulación del gas no convencional ("fracking") en España, Documento Funseam, 005-2015, p. 12.
} 
texto, mediante modificaciones realizadas al texto original y aprovechando las capacidades competenciales de la comunidad autónoma, a fin de defender jurídicamente el reconocimiento de tan amplia reivindicación social. En este sentido, los promotores de la iniciativa debían enmendar su propio texto, pero, por motivos reglamentarios de la Cámara vasca, ello solo era posible a través de las enmiendas presentadas por alguno de los grupos parlamentarios. De esta manera, los grupos parlamentarios del PSE-EE y EH Bildu presentan enmiendas dirigidas a hacer efectiva la prohibición bajo el amparo del ámbito competencial de la CAPV.

Así pues, el PSE-EE presenta enmiendas ${ }^{93}$ con la finalidad de establecer el filtro legal del ámbito competencial de la regulación del régimen del suelo, mientras que el grupo EH Bildu es el que registra más enmiendas ${ }^{94}$ al texto original, invocando tres filtros legales (véase tabla 2) que permitirían actuar a las instituciones de la CAPV dentro del marco competencial establecido ${ }^{95}$. Así, en lugar de apostar por prohibiciones genéricas y totales que chocarían con el marco jurídico básico español, tal y como quedó demostrado en los casos de Cantabria, La Rioja y Navarra, se opta por una vía más parecida a la catalana.

El grupo parlamentario promotor de la nueva articulación jurídica plantea configurar un "triple filtro legal" que prohíba el uso del fracking de manera efectiva y sin posibilidades jurídicas de que el ámbito competencial legal español pueda invalidar lo aprobado en la CAPV.

\footnotetext{
${ }^{93}$ PARLAMENTO VASCO, Enmiendas del grupo parlamentario "Socialistas Vascos - Euskal Socialistak" a la proposición de ley de medidas adicionales de protección medioambiental para la extracción de hidrocarburos no convencionales y la fractura hidráulica o "fracking". Recuperado el 10 de marzo de 2016, de http://www.legebiltzarra.eus/irud/10/00/029941.pdf.

${ }^{94}$ PARLAMENTO VASCO, Enmiendas del grupo parlamentario "Euskal Herria BILDU” a la proposición de ley de medidas adicionales de protección medioambiental para la extracción de hidrocarburos no convencionales y la fractura hidráulica o "fracking". Recuperado el 10 de marzo de 2016, de http://www.legebiltzarra.eus/irud/10/00/029947.pdf.

${ }^{95}$ PNV y PP adujeron las actuaciones previas del Tribunal Constitucional para negarse a apoyar la ILP. En el caso concreto del PNV, en las enmiendas a la ILP que registró el 18 de mayo de 2015 proponía una moratoria para que durante cinco años no se pudiese usar esta técnica para explorar y explotar hidrocarburos ni gas. Así, el PNV señalaba que no era partidario de que el Parlamento aprobase una ley que prohibiese esta técnica porque las comunidades autónomas no pueden prohibir, de forma absoluta $\mathrm{e}$ incondicionada, una técnica de investigación y extracción de hidrocarburos si el Estado la permite en su normativa básica. Además, para justificar la moratoria, apelaba al principio de precaución o cautela, y proponía la creación de una comisión científica independiente para analizar la evolución del fracking y la aparición de nuevas técnicas para extraer gas no convencional. Sin embargo, el 17 de junio de 2015 esta moratoria no fue aprobada por la Ponencia del Parlamento.
} 
A continuación se detallan los tres filtros legales utilizados sobre la base de las competencias propias en materia de suelo y aguas de la CAPV y de la facultad de las comunidades autónomas para dictar normas adicionales de protección ambiental (art. 149.1.23 CE) $)^{96,97,98}$.

\subsection{Primer filtro: la vía catalana}

El primer filtro legal para impedir el fracking en la CAPV se basa en el ejemplo catalán.

El 27 de marzo de 2015, el BOE publicaba un auto del Tribunal Constitucional por el que se levantaba la suspensión del artículo 167.1 de la Ley catalana 2/2014, de 27 de enero, de medidas fiscales, administrativas, financieras y del sector público. Dicho artículo establecía lo siguiente: "En la explotación de recursos naturales en suelo no urbanizable, en el caso de aprovechamiento de hidrocarburos, no está permitida la utilización de la tecnología de la fracturación hidráulica cuando pueda tener efectos negativos sobre las características geológicas, ambientales, paisajísticas o socioeconómicas de la zona, o en relación con otros ámbitos competenciales de la Generalitat". Por lo tanto, se condiciona el empleo del fracking en el marco competencial autonómico.

De ese modo, utilizando un texto muy similar al admitido por el Tribunal Constitucional para Cataluña, se modifica el artículo 28 de la Ley 2/2006, de 30 de junio, de Suelo y Urbanismo (véase tabla 2).

Este precepto utiliza en el ámbito formal la competencia exclusiva de la CAPV en materia de ordenación del territorio y urbanismo recogida en el artículo 10.31 del Estatuto de Autonomía del País Vasco (EAPV) ${ }^{99}$. En el ámbito material, constituye una medida adicional de protección que eleva el grado de preservación del medio ambiente frente a los efectos negativos que puede provocar sobre este el uso de la técnica de la fracturación hidráulica. Desde esta perspectiva, la prohibición pretende establecer un nivel de protección superior al mecanismo de evaluación ambiental previsto en la

\footnotetext{
${ }^{96}$ SERRANO, M., La regulación... cit., p. 18.

${ }^{97}$ IRIONDO, I., "EH Bildu introduce un triple filtro legal para poder impedir el fracking", Gara $(15 / 05 / 2015)$.

98 IRIONDO, I., “EH Bildu cree tener una vía legal para evitar el fracking”, Gara (23/04/2015).

${ }^{99}$ BOE, núm. 306, de 18 de diciembre de 1979. Recuperado el 11 de marzo de 2016, de https://www.boe.es/buscar/pdf/1979/BOE-A-1979-30177-consolidado.pdf.
} 
normativa básica sobre medio ambiente, que tiene el carácter de estándar mínimo susceptible de ser mejorado. Por lo tanto, la norma examinada encontraría amparo en el artículo 11.1.a) del EAPV.

Ahora bien, el contenido restrictivo de la modificación del artículo 28 de la Ley 2/2006 no se formula con carácter absoluto para evitar el choque con el contenido de la base estatal en materia de energía. En este sentido, cabe recordar que el Tribunal Constitucional ha reconocido la posibilidad de que las comunidades autónomas, para alcanzar una finalidad medioambiental, puedan prohibir la actividad minera en casos concretos (Sentencia del Tribunal Constitucional 64/1982, fundamento jurídico $6^{100}$ ), si bien nunca con carácter general.

Así, con el fin de ajustar el objetivo de protección medioambiental a la norma básica estatal en materia de régimen energético, en la mencionada modificación se concretan las circunstancias o supuestos en los que se prohíbe el uso de la técnica de fracturación hidráulica. De esta manera, se podrá limitar la técnica en función de las características geológicas, ambientales, paisajísticas o socioeconómicas de cada zona o en relación con otros ámbitos competenciales de la CAPV.

Este filtro, tras la reciente sentencia del Tribunal Constitucional de 4 de abril de 2016, que declaraba la inconstitucionalidad del mencionado artículo 167.1 de la Ley catalana 2/2014, de 27 de enero, de medidas fiscales, administrativas, financieras y del sector público, parecería estar destinado a correr la misma suerte. Ahora bien, conviene realizar una lectura detallada del artículo para observar que la redacción no es idéntica, ya que en el caso de la Ley vasca se dice lo siguiente:

En terrenos clasificados como suelo no urbanizable, en el caso de aprovechamiento de hidrocarburos, no está permitida la tecnología de la fractura hidráulica, cuando pueda tener efectos negativos sobre las características geológicas, ambientales, paisajísticas o socioeconómicas de la zona, o en relación con otros ámbitos competenciales de la Comunidad Autónoma Vasca, en función de lo que establezcan los instrumentos de ordenación territorial, urbanística y/o ambiental [art. 3].

La frase final que remite a los instrumentos de ordenación territorial, urbanística y/o medioambiental no aparece en el texto de la Ley catalana. Aspecto este, a la vista de la

\footnotetext{
${ }^{100}$ STC 64/1982, de 4 de noviembre de 1982. Recuperado el 11 de marzo de 2016, de http://hj.tribunalconstitucional.es/en/Resolucion/Show/106.
} 
reciente sentencia del Tribunal Constitucional, que no es baladí, ya que el legislador vasco ha acotado con esa redacción los instrumentos de ordenación territorial, urbanística y/o ambiental que, con la correspondiente motivación, pueden prohibir el fracking sobre la base de las consecuencias negativas que esta práctica puede provocar en los ámbitos reseñados.

Es la falta de determinación lo que la reciente sentencia del Tribunal Constitucional achaca al legislador catalán, a quien atribuye una intención de discrecionalidad a la hora de prohibir la práctica de la fractura hidráulica en todo el suelo no urbanizable de Cataluña, lo que el Tribunal considera una prohibición absoluta. En el caso de la Ley vasca, se concretan perfectamente los instrumentos en función de los cuales se pueden establecer los efectos negativos que llevarían a no permitir la técnica de la fractura hidráulica.

De hecho, es una remisión que tiene toda la lógica. Respecto a los instrumentos de ordenación territorial, no hay que olvidar que, en el marco de la competencia exclusiva de la CAPV en materia de ordenación del territorio, esta cuenta con planes territoriales sectoriales elaborados por los departamentos competentes del Gobierno Vasco en materias tales como: sector agroforestal, márgenes de ríos y arroyos, zonas húmedas y protección y ordenación del litoral, ámbitos todos ellos donde resulta lógico establecer de manera motivada el alcance y las limitaciones pertinentes a una técnica como la fractura hidráulica.

En cuanto a los instrumentos de ordenación urbanística, conviene recordar que no se fija una prohibición general de las actividades relacionadas con la práctica de la fractura hidráulica, sino que, ante la posibilidad de que el órgano competente en materia de planificación urbanística realice una valoración ponderada entre el interés energético y la protección medioambiental, y sobre la base de los efectos negativos que la utilización del fracking pueda generar, establece prohibiciones concretas y singulares en la ordenación urbanística. Aspecto este que, como bien recuerda el profesor René Santamaría, tiene el aval del Tribunal Supremo ${ }^{101}$.

Por último, la mención que el artículo 3 de la Ley vasca realiza a los instrumentos de ordenación medioambiental reafirma un aspecto ya recogido en la legislación vasca de protección del medio ambiente. En este sentido, el artículo 17 de la Ley 16/1994, de 30

${ }^{101}$ SANTAMARÍA, “Las claves..." cit., p. 16. 
de junio, de Conservación de la Naturaleza del País Vasco, recoge en su apartado cuarto que "dentro de los límites de los espacios naturales protegidos y sus zonas de afección se prohibirán las actividades extractivas que resulten incompatibles con los valores ambientales que se protegen. Serán los instrumentos de planificación y/o gestión de cada espacio natural protegido los que determinen dicha incompatibilidad, motivando adecuadamente la incompatibilidad de las actividades con los valores medioambientales y los criterios de protección de dichos espacios y de sus zonas de afección”.

Por lo tanto, una herramienta de ordenación medioambiental como es un plan de ordenación de los recursos naturales de un parque natural puede declarar incompatible, prohibir, la realización de un sondeo de extracción de hidrocarburos no convencionales por medio de la práctica de la fractura hidráulica al considerar que no es compatible con los valores ambientales de dicho espacio.

\subsection{Segundo filtro: evaluación estratégica}

El segundo filtro se basa en la recomendación del 22 de enero de 2014 de la Comisión Europea relativa a unos principios mínimos para la exploración y producción de hidrocarburos (como el gas de esquisto) mediante la fracturación hidráulica de alto volumen.

En el apartado 3.1 de dicha recomendación, se señala lo siguiente:

Antes de conceder una autorización para una exploración y/o producción de hidrocarburos que puedan dar lugar a la aplicación de la fracturación hidráulica de alto volumen, los Estados miembros deben preparar una evaluación ambiental estratégica para prevenir, gestionar y reducir los impactos y los riesgos para la salud humana y el medio ambiente. Esa evaluación debe realizarse sobre la base de los requisitos de la Directiva 2001/42/CE.

Así, se fija por ley que cualquier plan que recoja el uso del fracking y, en especial, la Estrategia Energética de Euskadi se sometan al procedimiento de evaluación ambiental estratégico (véase tabla 2).

Este precepto hay que interpretarlo junto con la disposición transitoria segunda de la misma Ley, que establece:

La obligatoriedad a que se refiere el artículo 4 (de evaluación estratégica) de la presente ley, además de aplicarse a los planes que se tramiten con posterioridad a la 
entrada en vigor de la presente ley, se aplicará asimismo a los planes, programas y estrategias en vigor aprobados definitivamente con posterioridad al 21 de julio de 2006. No se concederán permisos para realizar perforaciones o sondeos exploratorios con objeto de explotar hidrocarburos no convencionales, en tanto no se concluya la tramitación completa de la evaluación medioambiental estratégica a que se refiere el párrafo anterior.

La fecha del 21 de julio de 2006 alude a la entrada en vigor en el Estado español de la Directiva 2001/42/CE, relativa a la evaluación de los efectos de determinados planes y programas en el medio ambiente ${ }^{102}$.

\subsection{Tercer filtro: Ley de Aguas}

El tercer filtro legal se basa en la reforma de la Ley 1/2006, de 23 de junio, de Aguas (véase tabla 2). A diferencia del primer filtro, en esta ocasión se utiliza a nivel formal una norma del ámbito medioambiental, mientras que en el aspecto material se hace referencia a una figura, concretamente al mapa de vulnerabilidad a la contaminación de los acuíferos de la CAPV. Dicha figura está plenamente incardinada en la competencia exclusiva en materia de ordenación del territorio del artículo 10.31 del EAPV, ya que las Directrices de Ordenación del Territorio (instrumento que establece el marco regulador básico en la ordenación del territorio en la CAPV) disponen que los mapas de vulnerabilidad son el marco referencial para el establecimiento de áreas de vulnerabilidad de las aguas subterráneas.

Ahora bien, la norma vasca determina que la prohibición del uso del fracking solo se da en el caso de que el riesgo de vulnerabilidad sea medio, alto o muy alto, no así cuando la vulnerabilidad sea baja, muy baja o inapreciable, por lo que no se trata de una prohibición absoluta, sino que habrá que analizar caso por caso con el fin de determinar la clasificación a la que obedece cada uno de los espacios de que se traten. Asimismo, a los efectos de clarificar que el nuevo párrafo segundo del apartado 1 del artículo 29 de la Ley de Aguas no contempla una prohibición absoluta del uso del fracking, hay que poner en conexión este nuevo párrafo segundo con el primero de dicho artículo 29, que se refiere a una prohibición de contaminación o degradación y otras normas generales, salvo autorización administrativa previa y expresa de la Agencia Vasca del Agua y sin

\footnotetext{
${ }^{102}$ BOCE, núm. L 197, de 21 de julio de 2001. Recuperado el 11 de marzo de 2016, de https://www.boe.es/doue/2001/197/L00030-00037.pdf.
} 
perjuicio de cualquier otra autorización administrativa legalmente exigible. El nuevo párrafo 2 añade en este sentido que queda prohibido el uso de la técnica de la fractura hidráulica para la explotación de hidrocarburos en aquellos espacios clasificados como de riesgo de vulnerabilidad media, alta o muy alta en el mapa de vulnerabilidad a la contaminación de acuíferos de la CAPV.

De la interpretación conjunta e integrada de ambos párrafos se desprende que, aun existiendo la prohibición en los supuestos previstos en la Ley, se faculta al órgano competente de la CAPV en materia de aguas para exceptuar esas prohibiciones legalmente previstas por medio de una autorización previa y expresa. Por lo tanto, puede decirse que no existe una prohibición absoluta en este ámbito desde una doble perspectiva: a) existen tres espacios clasificados en el mapa de vulnerabilidad que no se encuentran sometidos a la prohibición de uso del fracking; y b) la Ley faculta al órgano competente de la CAPV en materia de aguas para que pueda dictar autorizaciones expresas excepcionando las posibles prohibiciones que pudieran derivarse de las previsiones legales citadas.

Tabla 2: Los tres filtros legales para poder impedir el fracking en la CAPV

\begin{tabular}{|c|c|}
\hline & Los tres filtros legales contra el fracking en la CAPV \\
\hline $\begin{array}{l}\text { 1. }{ }^{\text {er }} \text { filtro } \\
\text { (La vía } \\
\text { catalana) }\end{array}$ & $\begin{array}{l}\text { Se modifica el artículo } 28 \text { de la Ley } 2 / 2006 \text {, de } 30 \text { de junio, de Suelo y } \\
\text { Urbanismo }^{103} \text {, creando un nuevo punto } 7 \text { con el siguiente texto: "En terrenos } \\
\text { clasificados como suelo no urbanizable, en el caso de aprovechamiento de } \\
\text { hidrocarburos, no está permitida la tecnología de la fractura hidráulica, cuando pueda } \\
\text { tener efectos negativos sobre las características geológicas, ambientales, paisajísticas } \\
\text { o socioeconómicas de la zona, o en relación con otros ámbitos competenciales de la } \\
\text { Comunidad Autónoma Vasca, en función de lo que establezcan los instrumentos de } \\
\text { ordenación territorial, urbanística y/o ambiental". (Basado en el artículo } 167.1 \text { de la } \\
\text { Ley catalana } 2 / 2014 \text {, de } 27 \text { de enero, de medidas físcales, administrativas, financieras } \\
\text { y del sector público.) }\end{array}$ \\
\hline $\begin{array}{c}\mathbf{2 .}^{\mathbf{0}} \text { filtro } \\
\text { (Evaluación } \\
\text { estratégica) }\end{array}$ & $\begin{array}{l}\text { Se aprueba, en relación con el impacto ambiental, lo siguiente: "En general, } \\
\text { cualquier plan, programa o estrategia sectorial que contemple la fractura hidráulica } \\
\text { para la explotación de hidrocarburos, especialmente la estrategia energética vasca, } \\
\text { deberá contar con una evaluación medioambiental estratégica". (Basado en el } \\
\text { apartado } 3.1 \text { de la recomendación de la Comisión Europea relativa a unos principios } \\
\text { mínimos para la exploración y producción de hidrocarburos - como el gas de }\end{array}$ \\
\hline
\end{tabular}

\footnotetext{
${ }^{103}$ BOE, núm. 266, de 4 de noviembre de 2011. Recuperado el 12 de febrero de 2016, de https://www.boe.es/boe/dias/2011/11/04/pdfs/BOE-A-2011-17400.pdf.
} 


\begin{tabular}{|c|c|}
\hline & esquisto- mediante la fracturación hidráulica de alto volumen.) \\
\hline $\begin{array}{c}\text { 3. }{ }^{\text {er }} \text { filtro } \\
\text { (Ley de } \\
\text { Aguas) }\end{array}$ & $\begin{array}{l}\text { Se añade un nuevo párrafo al artículo } 29.1 \text { de la Ley } 1 / 2006 \text {, de } 23 \text { de junio, de } \\
\text { Aguas }^{104} \text { : "En este sentido, queda prohibido el uso de la técnica de la fractura } \\
\text { hidráulica para la explotación de hidrocarburos en aquellos espacios clasificados } \\
\text { como de riesgo de vulnerabilidad media, alta o muy alta en el mapa de vulnerabilidad } \\
\text { a la contaminación de los acuíferos de la CAV". }\end{array}$ \\
\hline
\end{tabular}

Fuente: elaboración propia

Una vez aprobada por la ponencia del Parlamento (con los votos de EH Bildu, PSE-EE y PP), pasada por la comisión pertinente y aprobada en el Pleno del Parlamento, la ILP consiguió cambiar la Ley 2/2006, de 30 de junio, de Suelo y Urbanismo, y la Ley 1/2006, de 23 de junio, de Aguas, impidiendo en la práctica el uso de la técnica del fracking en la CAPV y haciendo obligatoria la solicitud de una evaluación ambiental estratégica para cualquier plan, programa o estrategia sectorial que incluya el fracking, con la prohibición de cualquier sondeo mientras no esté redactada. De modo que, con objeto de evitar posibles recursos contra la norma, se eliminó la prohibición genérica, si bien la Ley 6/2015, de 30 de junio, de medidas adicionales de protección medioambiental para la extracción de hidrocarburos no convencionales y la fractura hidráulica o fracking, eleva tanto los requisitos para poder utilizar la técnica que prácticamente la impide.

Así, las disposiciones y los requisitos hacen prácticamente inviable el desarrollo de un proyecto de este tipo, y solo un pronunciamiento judicial en contra de la norma vasca reabriría la puerta del fracking en la CAPV. De hecho, el Gobierno Vasco asumió que tendría que paralizar todos los proyectos de investigación y exploración que desarrollaba en esos momentos a través de la Sociedad de Hidrocarburos de Euskadi $\left(\right.$ SHESA) ${ }^{105}$.

\section{Impugnación de la Ley 6/2015, de 30 de junio, ante el Tribunal Constitucional}

El 30 de junio de 2015 el Gobierno central anunció que impugnaría ante el Tribunal Constitucional, en su totalidad, la Ley 6/2015, de 30 de junio, de medidas adicionales de

\footnotetext{
${ }^{104}$ BOE, núm. 266, de 4 de noviembre de 2011. Recuperado el 12 de febrero de 2016, de https://www.boe.es/boe/dias/2011/11/04/pdfs/BOE-A-2011-17399.pdf.

${ }^{105}$ EL CORREO, "Euskadi reforma las leyes de suelo y agua para impedir el fracking", El correo (01/07/2015).
} 
protección medioambiental para la extracción de hidrocarburos no convencionales y la fractura hidráulica o fracking, por considerar que vulnera principios constitucionales.

El Gobierno central recordaba que la Ley 6/2015, de 30 de junio, en su artículo 3, "no establece de forma expresa una prohibición absoluta de exploración, investigación y explotación de hidrocarburos mediante la técnica del fracking. Ahora bien, se establece una prohibición de tipo general relativa a los terrenos clasificados como suelo no urbanizable cuando pueda tener efectos negativos en relación con cualquier ámbito competencial de la CAPV y en función de lo que establezcan los instrumentos de ordenación territorial, urbanística y/o ambiental".

Y añadía: "En la práctica, cabría valorar si lo que se establece es una prohibición absoluta. Más exactamente, se faculta a las Administraciones competentes en materia de ordenación del territorio, urbanismo y vivienda y medio ambiente, para establecer prohibiciones absolutas en sus respectivos ámbitos territoriales y competenciales mediante los instrumentos de ordenación que les corresponde aprobar”.

También subrayaba que "el precepto afecta a todo el territorio del País Vasco que no sea suelo urbano y la prohibición puede establecerse cuando esté afectada cualquier competencia de la CAPV", para destacar que "la CAPV no puede establecer prohibiciones generales de esta clase".

En este sentido, citaba las leyes contra el fracking de Cantabria y La Rioja, que han establecido "previsiones absolutas" en torno a este sistema de extracción, y destacaba que las dos han sido declaradas inconstitucionales y, por lo tanto, nulas, por las SSTC $106 / 2014$ y $134 / 2014^{106,107}$.

En este escenario, el Estado, tras activar el mecanismo que le concede el artículo 33.2 de la Ley Orgánica del Tribunal Constitucional ${ }^{108}$, convoca la Comisión Bilateral de

\footnotetext{
${ }^{106}$ PARLAMENTO VASCO, Nota sobre la Ley 6/2015, de 30 de junio, de medidas adicionales de protección medioambiental para la extracción de hidrocarburos no convencionales y la fracturación hidráulica o fracking. Recuperado el 11 de marzo de 2016, de http://www.legebiltzarra.eus/irud/10/00/032297.pdf.

${ }^{107}$ EUROPA PRESS, El Gobierno avisa al Ejecutivo vasco de que las Leyes de Vivienda y Fracking son inconstitucionales. Recuperado el 5 de mayo de 2016, de http://www.europapress.es/nacional/noticiagobierno-rajoy-avisa-ejecutivo-vasco-leyes-vivienda-fracking-son-inconstitucionales20150726193724.html.

${ }^{108}$ Ley Orgánica 2/1979, de 3 de octubre, del Tribunal Constitucional, Texto consolidado e integrado con las modificaciones introducidas por las Leyes Orgánicas 8/1984, 4/1985, 6/1988, 7/1999 y 1/2000 y con expresión particularizada de las reformas conforme a las Leyes Orgánicas 6/2007, de 24 de mayo, y 1/2010, de 19 de febrero. Recuperado el 24 de abril de 2016, de
} 
Cooperación Administración del Estado-Administración de la Comunidad Autónoma del País Vasco e inicia las negociaciones pertinentes ${ }^{109}$. Aspecto este que amplía el plazo para interponer el recurso de inconstitucionalidad hasta los nueve meses desde la publicación de la Ley, lo cual situaba el 9 de abril de 2016 como fecha clave para saber cuál sería el recorrido de esta.

Después de que la negociación prevista en el artículo 33.2 de la Ley del Tribunal Constitucional fuera infructuosa y tras avalar el Consejo de Estado que existen fundamentos jurídicos suficientes, el 8 de abril de 2016 el Consejo de Ministros solicita al presidente del Gobierno la interposición de un recurso de inconstitucionalidad contra determinados preceptos de la Ley 6/2015, de 30 de junio, de medidas adicionales de protección medioambiental para la extracción de hidrocarburos no convencionales y la fractura hidráulica o fracking ${ }^{110}$.

En este, se señala que "la Ley del País Vasco faculta a las Administraciones Públicas vascas para vedar el uso de la tecnología de fractura hidráulica en los supuestos en que pueda tener efectos negativos sobre las características geológicas, ambientales, paisajísticas o socioeconómicas de la zona y sobre otras competencias relacionadas con el aprovechamiento de hidrocarburos". Y se añade lo siguiente:

[...a]nte un caso similar, el Tribunal Constitucional ha anulado las leyes de las CCAA de Cantabria y La Rioja que prohibían el uso de la técnica de fractura hidráulica, por lo que se entiende que esa doctrina es trasladable al caso actual en los aspectos siguientes:

- La ley vasca vulnera la normativa básica estatal sobre régimen minero y energético.

- Las competencias de la Comunidad Autónoma de desarrollo y ejecución en materia de medio ambiente en ningún caso la facultan para vaciar de sus competencias al Estado, especialmente cuando la normativa básica estatal establece

http://www.tribunalconstitucional.es/es/tribunal/normasreguladoras/Lists/NormasRegPDF/Normas\%20Re guladoras/leyorgtrib.pdf.

${ }^{109}$ BOPV, núm. 176, de 16 de septiembre de 2015. Recuperado el 11 de marzo de 2016, de http://www.jusap.ejgv.euskadi.eus/r47-opvapps/es/bopv2/datos/2015/09/1503897a.pdf.

${ }^{110}$ LA MONCLOA, GOBIERNO DE ESPAÑA, Recurso de inconstitucionalidad contra la Ley del País Vasco de medidas de protección medioambiental ante la fractura hidráulica, Consejo de Ministros de 8 de abril de 2016. Recuperado el 24 de abril de 2016, de

http://www.lamoncloa.gob.es/consejodeministros/referencias/Paginas/2016/refc20160408.aspx. 
el sometimiento de todos los proyectos a la previa declaración de impacto ambiental.

- La norma establece que se aplicará por igual a todos los permisos, tanto a los ya concedidos o en tramitación como a las solicitudes que se formulen a partir de la entrada en vigor de la norma, por lo que se vulnera el principio de seguridad jurídica.

- La norma vasca incluye en su ámbito los hidratos de metano enterrados en el mar y, a este respecto, el Tribunal Constitucional ha señalado que las CCAA sólo pueden ejercer competencias sobre el mar si está previsto en los Estatutos de Autonomía o lo exige la naturaleza de la competencia a ejercer, pero ninguna de estas dos circunstancias concurre en este caso.

\section{CONCLUSIONES}

Los recursos energéticos fósiles de fácil acceso y de gran rendimiento, que han sido una de las claves del modelo económico actual, basado en la ilusión de un crecimiento ilimitado, están mostrando signos evidentes de agotamiento. El petróleo, por ejemplo, como principal exponente de los combustibles fósiles, ha superado ya el peak oil (cénit petrolero o punto máximo de producción), y su tasa de producción ha comenzado ya a declinar considerablemente.

En este contexto, las grandes industrias energéticas, junto con los gobiernos de algunos Estados, buscan responder a esta crisis del paradigma económico y energético. Así, mantienen su apuesta por seguir extrayendo los recursos fósiles. Sin embargo, a medida que avanza la explotación de dichos recursos, su acceso resulta más costoso física y económicamente. Por ello, las empresas se ven obligadas a emplear nuevas técnicas de extracción, entre las que se encuentra la fractura hidráulica o fracking.

No obstante, la necesidad de emplear técnicas más complejas y costosas para acceder a bolsas de recursos fósiles más inaccesibles y más escasos ponen en duda la viabilidad económica futura de las técnicas de extracción no convencionales. Sin embargo, al margen de la vertiente económica y la rentabilidad social de este tipo de técnicas, entre los opositores al fracking cobran especial relevancia los perjuicios que esta técnica puede acarrear a la salud de las personas y al medioambiente. De esta preocupación nace la oposición social a esta técnica, que beneficia, según sus detractores, un modelo 
socialmente injusto y ecológicamente insostenible que solo serviría para dar continuidad a un paradigma económico y energético sin futuro.

Al calor de esta reflexión surgen los movimientos de oposición al fracking en muchos lugares en el mundo, así como en la CAPV. Como respuesta a esta preocupación surge la iniciativa legislativa popular (Proposición de Ley de medidas adicionales de protección medioambiental para la extracción de hidrocarburos no convencionales y la fractura hidráulica o fracking) analizada en este artículo, cuyo objetivo es prohibir esta técnica en el territorio afectado y que fue aprobada como Ley 6/2015, de 30 de junio, de medidas adicionales de protección medioambiental para la extracción de hidrocarburos no convencionales y la fractura hidráulica o fracking. Como bien recoge la propia ILP, la sociedad vasca es consciente, cada vez en mayor grado, de la importancia de conservar y proteger el medio ambiente como valor jurídico al que todos tenemos derecho.

Al margen del grado de infalibilidad legal de la ley aprobada en el Parlamento Vasco, la plataforma impulsora de la iniciativa consideró que su aprobación suponía la culminación de todo un proceso jurídico e institucional. Sin entrar en mayor detalle sobre la tipología de cada iniciativa, cabe destacar que el movimiento social convirtió su reivindicación en una cuestión transversal que se trató en la mayoría de las instituciones de la CAPV: se aprobaron mociones en contra de la técnica en numerosos ayuntamientos; las Juntas Generales de cada territorio se pronunciaron en contra de la fractura hidráulica; y el Parlamento autonómico aprobó una ley que suponía el remate legal a todo el proceso jurídico e institucional. Cabe destacar que la plataforma contraria al fracking consiguió así cerrar, desde una perspectiva territorial y explotando al máximo las competencias de cada instancia, todas las puertas posibles jurídicamente a esta técnica.

De hecho, el rotundo éxito del movimiento, aunque imposible de cuantificar con criterios objetivos, no solo se materializa en la aprobación de la Ley. El proceso de presentación, tramitación y debate final también contribuyó a ganar presencia mediática y social. El movimiento vasco contra el fracking ha superado diversas etapas, con resultados positivos hasta el momento: de la preocupación social inicial se pasó a crear un movimiento articulado de contestación; sus acciones han influido en la opinión pública y en la opinión publicada por los medios de comunicación, y, como consecuencia, en las posturas políticas de los partidos con representación en las distintas 
instituciones; $\mathrm{y}$, finalmente, se ha presentado y aprobado una ley que aprovecha al máximo las competencias propias de la comunidad para impedir en la práctica esta técnica.

Tal y como se ha explicado, la notoriedad de la reivindicación de la plataforma ha permitido que la ILP supere con gran éxito requisitos administrativos como la recogida de firmas obligatoria. Además, merece recalcar que, ante el apoyo social, la tramitación de la iniciativa legislativa popular propició considerables cambios en las posturas políticas de algunas fuerzas con representación en la Cámara vasca. Finalmente, la disposición fue aprobada por dos tercios de la Cámara y ningún voto en contra (47 votos a favor; 28 abstenciones).

Sin embargo, el contexto legislativo y político a nivel de España, por una parte, y la jurisprudencia desarrollada por el Tribunal Constitucional en relación con el ámbito competencial, por otra, abocaba el texto vasco a una frágil efectividad jurídica. Los recursos interpuestos a otras leyes autonómicas contrarias al fracking hacían imprescindible una reformulación jurídica para aprovechar las competencias propias de la CAPV en busca del objetivo de prohibir esta técnica. Así, la declaración de nulidad de las leyes cántabra, riojana y navarra que prohibían, de forma genérica, la técnica de la fractura hidráulica propició la búsqueda de nuevas formas legales para prohibirla. Este ha sido, concretamente, el caso de Cataluña y la CAPV.

En la CAPV se optó por presentar una iniciativa legislativa popular tomando como base el modelo cántabro, navarro y riojano. Durante el trámite parlamentario se enmendó el articulado original, introduciendo una visión jurídica novedosa y aportando tres filtros legales con base en las competencias propias en materia de suelo y aguas de la CAPV. Mediante esta fórmula se busca conjugar el ámbito competencial propio de la comunidad autónoma con la facultad de las comunidades autónomas para dictar normas adicionales de protección ambiental con la finalidad de evitar una prohibición genérica y total, pero elevando tanto los requisitos que se exigen para permitir la técnica del fracking como para que en la práctica no se pueda utilizar.

Queda por ver qué sucederá tras el anuncio de impugnación de la Ley vasca por parte del Gobierno central. La reciente sentencia del Tribunal Constitucional que declara la inconstitucionalidad de la Ley catalana no augura un final diferente para la disposición normativa vasca. Ahora bien, tal y como hemos señalado a lo largo de este artículo, el filtro relativo a la legislación del suelo y del urbanismo no es idéntico en ambos casos; 
en este sentido, en el caso de la Ley vasca se concretan los instrumentos de ordenación en función de los cuales se pueden establecer prohibiciones motivadas a la técnica de la fractura hidráulica. Además, se han establecido otros dos filtros que encajan perfectamente, a priori, en el marco del reparto competencial entre el Estado y las comunidades autónomas, lo que permitiría augurar la validez constitucional de la Ley vasca.

\section{BIBLIOGRAFÍA}

ÁLVAREZ, E. y SUÁREZ, C., Gas no convencional: shale gas. Aspectos estratégicos, técnicos, medioambientales y regulatorios, Orkestra - Instituto Vasco de Competitividad, 2014.

ÁLVAREZ, M., "El aprovechamiento de hidrocarburos no convencionales mediante fracturación hidráulica", Revista General de Derecho Administrativo, 2014, pp. 1-43.

AYLlÓN, J. M., "El agua, sin gas, por favor: la controversia jurídica en torno al fracking en España”, eXtoikos, 2014, pp. 35-44.

BOQUERA, V. y JIMÉNEZ, J., “¿Puede el Fracking ser materia de acuerdo local?”, Cuadernos de Derecho Local (QDL), núm. 33, 2013, pp. 175-180.

BRADY, W., "Hydraulic Fracturing Regulation in the United States: The Laissez-Faire Approach of the Federal Government and Varying State Regulations", University of Denver, Grimshaw \& Harring, 2013, pp. 1-19.

CINGOTTI, N., Fracking: un pozo sin fondo, Dossier Informativo, marzo de 2014.

COMISIÓN EUROPEA, Final report on unconventional gas in Europe, 8 de noviembre de 2011.

COMISIÓN EUROPEA, Comunicación sobre la exploración y producción de hidrocarburos (como el gas de esquisto) utilizando la fracturación hidráulica de alto volumen en la UE, COM(2014) 23 final, 22 de enero de 2014.

COMISIÓN EUROPEA, Recomendación de la Comisión Europea relativa a unos principios mínimos para la exploración y producción de hidrocarburos (como el gas de esquisto) utilizando la fracturación hidráulica de alto volumen, 22 de enero de 2014. 
FERNÁNDEZ DE GATTA, D., “Aportaciones jurídicas al debate sobre la obtención de gas no convencional mediante la técnica de fractura hidráulica", Diario La Ley, 2014, pp. 1-23.

FERNÁNDEZ DE GATTA, D., "Regulación de la obtención de gas no convencional mediante la técnica de fractura hidráulica: situación en la Unión Europea y en España”, Revista Vasca de Administración Pública, núm. 8336, 2014, pp. 1331-1351.

FRACKING EZ ARABA, "Fracking, una apuesta peligrosa", Vitoria-Gasteiz, 2012.

INSTITUT DE DRETS HUMANS DE CATALUNYA, Declaración universal de derechos humanos emergentes, junio 2009.

JORDANO, J., "El fracking en el estrado: Recogiendo el guante verde arrojado por el tribunal constitucional a las comunidades autónomas", Revista Aragonesa de Administración Pública, núm. 45-46, 2015, pp. 9-34.

MARZO, M., "Recursos convencionales y no convencionales de petróleo y gas", Enseñanza de las Ciencias de la Tierra, 2008, pp. 218-228.

MOREU, E., "Marco jurídico de la extracción de hidrocarburos mediante fractura hidráulica (fracking)", Revista Catalana de Dret Ambiental, vol. III, núm. 2, 2012, pp. $1-43$.

PARLAMENTO EUROPEO, Repercusiones de la extracción de gas y petróleo de esquito en el medio ambiente y la salud, IP/A/ENVI/ST/2011-07, 2011, junio de 2011.

PARLAMENTO EUROPEO, Proyecto de informe sobre aspectos industriales, energéticos y otros del gas y del petróleo de esquisto, 2011/2309(INI), 25 de septiembre de 2012.

PARLAMENTO EUROPEO, Proyecto de informe sobre las repercusiones medioambientales de la extracción de gas y petróleo de Esquisto, 2011/2308(INI), 25 de septiembre de 2012.

PÉREZ DE AYALA, L. y ANTÓN, D., "Sobre la constitucionalidad de un anteproyecto de ley autonómica que contempla la prohibición absoluta de la actividad de extracción de gas no convencional en el territorio de una comunidad autónoma", Recuerda Girela, M. A. (coord.), Problemas prácticos y actualidad del Derecho administrativo, Civitas, 2014. 
RENEE, L.K., The Oil and Gas Industry's Exclusions and Exemptions to Major Environmental Statutes, Earthworks, Oil \& Gas Accountability Project, 2007.

SÁNDEZ, J. D., La fracturación hidráulica en la Unión Europea: Estado de la cuestión, Instituto Español de Estudios Estratégicos, 2014.

SÁNDEZ, J. D., "Fracturación hidráulica y Comunidades Autónomas: a propósito de dos proposiciones de ley presentadas en Andalucía", Actualidad Jurídica Ambiental, 2015, pp. 1-26.

SANTAMARÍA, R. J., "Las claves jurídicas del debate sobre el fracking”, Revista Catalana de Dret Ambiental, vol. V, núm. 1, 2014, pp. 1-38.

SERRANO, M., La regulación del gas no convencional ("fracking”) en España, Documento Funseam, 005-2015. 